\title{
TRAFFIC ACCIDENTS IN EGYPT -2 FACTORS AFFECT ON TRAFFIC ACCIDENTS IN EGYPT (HUMAN - PLACE - TIME)
}

\section{Sayed Abas Ali}

Department of Architecture, Faculty of Engineering Assiut University, Assiut, Egypt

(Received March 2, 2009 Accepted March 13, 2009)

Victims due to traffic accidents are more than 5000 of death and 22000 injures with different hurts, annually. Economical loses are $2 \%$ from national total income according data of Egyptian society for protection from traffic accidents. Traffic accidents consider the second reason for death in Egypt. $80 \%$ of victims are 15: 45 years old (age of offering). Objective of study is to investigate factors affect on traffic accidents, this study concentrate on (human, place, and time). Study includes (1) Introduction about how we carried out applications. (2) Factors of human affect on traffic accidents: behaviors of drivers and pedestrians. (3) Investigate reasons of traffic accidents due to place. (4) Investigate time of traffic accidents about hours /day / week /month / season / year. (5) Arrive to conclusions and remarks according analysis of study. (6) Put recommendations about how to decrease consequences of traffic accidents in Egypt.

KEYWORDS: Traffic accidents - Egypt - Human - Place - Time

$$
\begin{aligned}
& \text { حوادث المرور بمصر - 2- } \\
& \text { (المتغيرات المؤثرة فى حوادث المرور بمصر) } \\
& \text { (الإنسان - المكان - الزمان) } \\
& \text { قسم العدارة - كلية الهنيسة جاس علية أسبوط - مصر } \\
& \text { ت: } 0882286504 \text { ف: } 0882332553 \text { جوال: } 0107651982 \\
& \text { sayed142@yahoo.com }
\end{aligned}
$$

عدد الضحايا المصريين في حوادث السيارات قد ارتفع الى اكثر من 5 آلاف قتيل سنوياً و 22 ألف

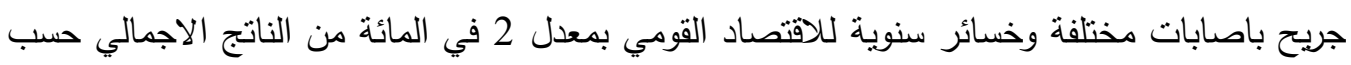
احدث بيانات للجمعية المصرية للحماية من حوادث الطرق. تعتبر حوادث السيارات السبب الثاني لوفاة

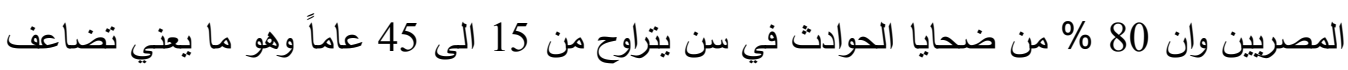

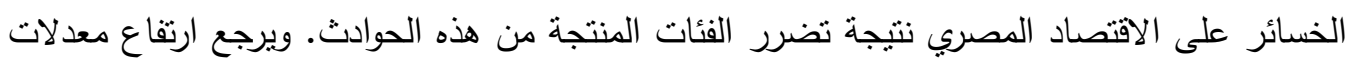


الحوادث في مصر الى سلوكيات السائقين غير الددربين على القيادة جيداً، وقال ان 70 \% من هذه الحوادث بسبب تلك السلوكيات الخاطئة و 20 \% من الأسباب نرجع لسلامة المركبات و 10 \% لسوء الطرق. [1]

تهدف هذه الجزئية من الدراسة الى الكثف عن المتغيرات المؤثرة فى حوادث المرور و نسبة المشاركة فيها، (تختص هذه الدراسة ببعض المتغيرات المؤثرة فى حوادث المرور كالإنسان (سلوكيات السائق)،

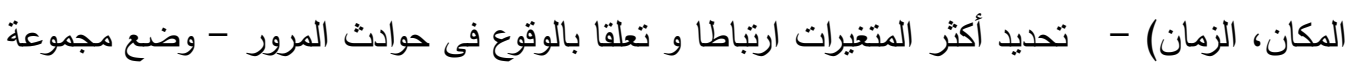
من التوصيات لكى يستفاد منها فى رسم السياسات التى تساعد على التقليل من حوادث المرور، و و تقليل

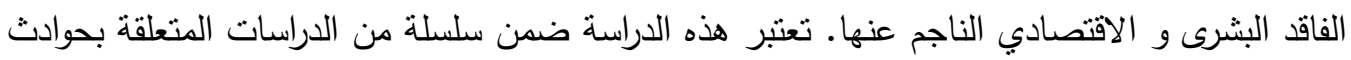
المرور و التى قام بها الباحث. ويتكون البحث من (1) المقدمة، و تتتاول عرضا لإشكالية البحث و الفرضية و الأهداف، و المنهجية.

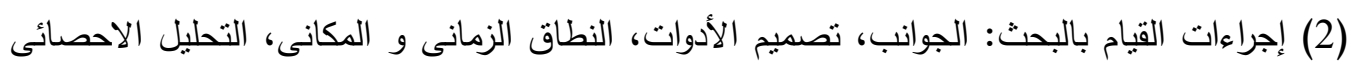

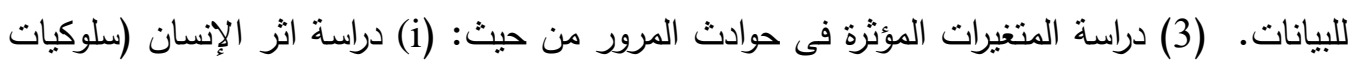

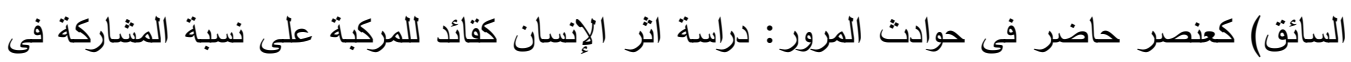

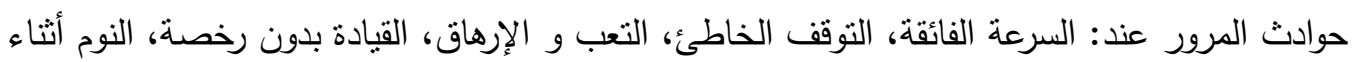

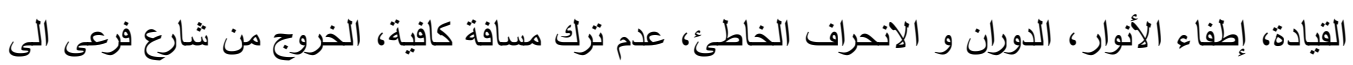

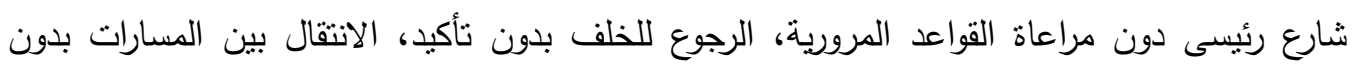

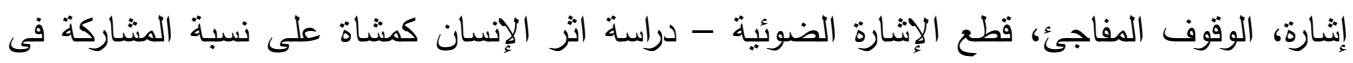
حوادث المرور عند قيامه: بالعبور المخالف، السير فى طريق السبارات، العبور العبه بين مركبنتين، العبور

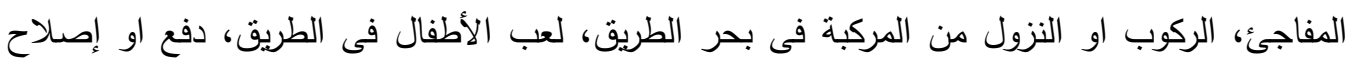

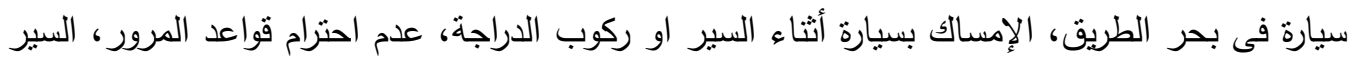
عكس الاتجاه فى بحر الطريق. (ii) دراسة حوادث المرور فى المدينة المصرية، المنطقة و المكان:

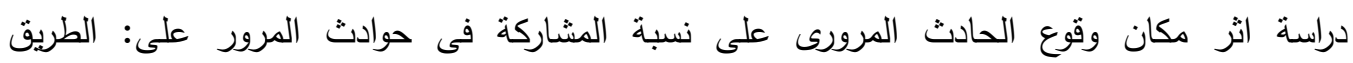
الصحراوى، الطريق رئيسى، الفرعى، المستقيم، المنحنى، عند الكوبرى، النفق، الأنواع المختلفة لتقاطعات

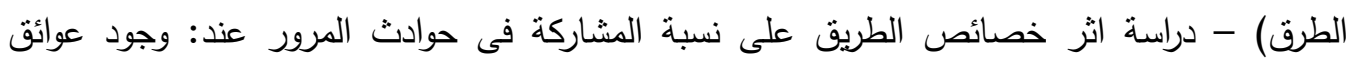

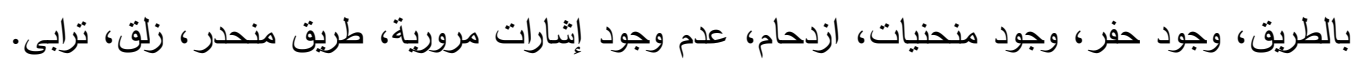
(iii)

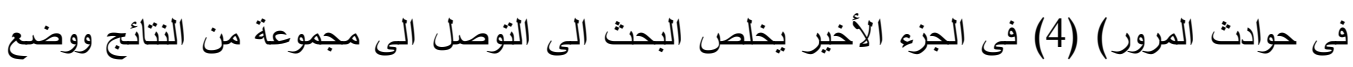

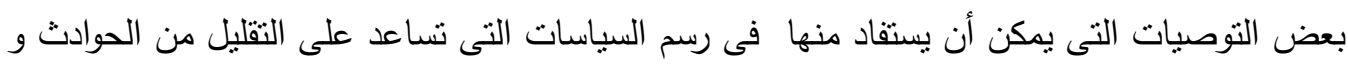

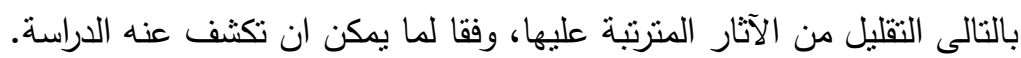




\section{1}

تركز الاهتمام فى الفترة الأخيرة على دراسات المرور، سواء على المستوى العالمى، او المصرى. و قد

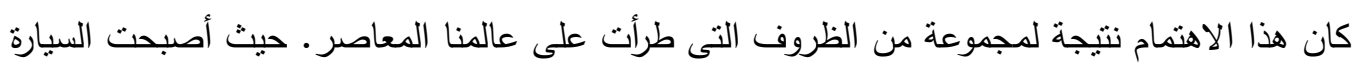

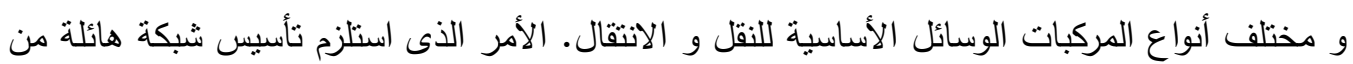

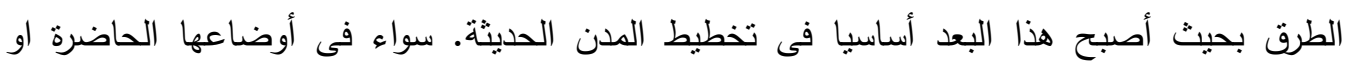

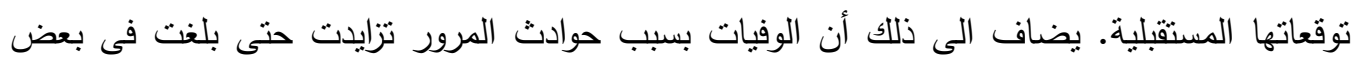

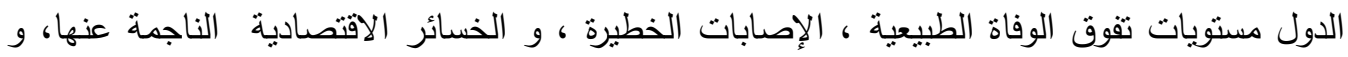

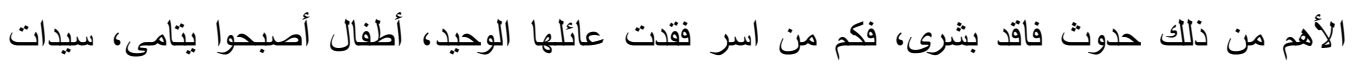

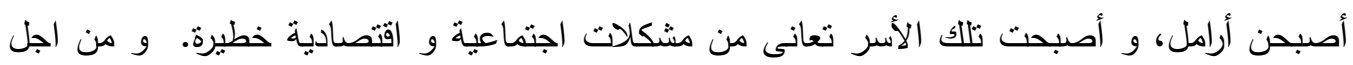
ذللك برزت دراسات المرور و ظواهره فى مقدمة الموضوعات و القضايا التى نستحق البحث و الدراسة.

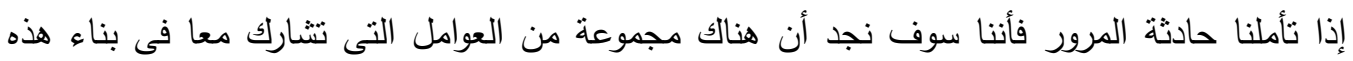

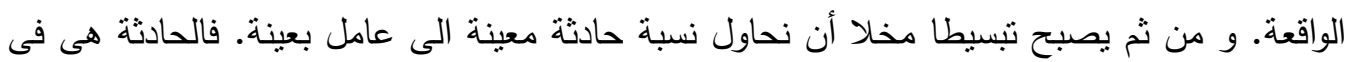

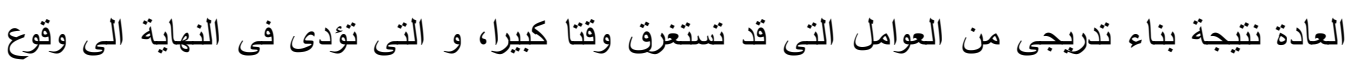
الحادثة. فالحادثة يرتكبها إنسان معين و قد يذهب ضحيتها إنسان آخر ـ فالعنصر البشرى حاضر دائما

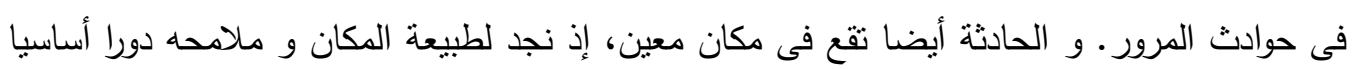
فى وقوع الحادثة. و هى تقع فى زمان معين قد يكون اللحظة التى وقعت فيها الحادثة، و قد في يبدأ زمان

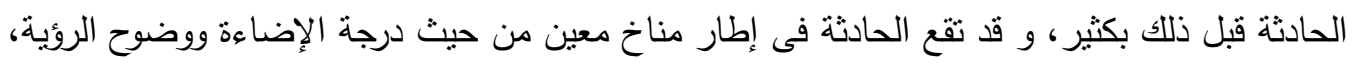

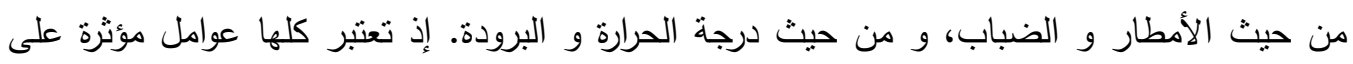

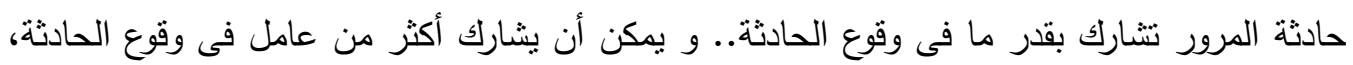

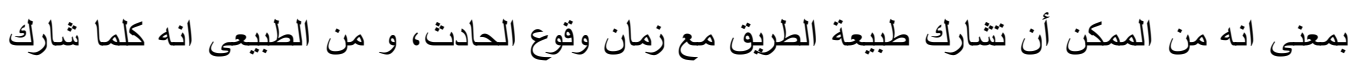

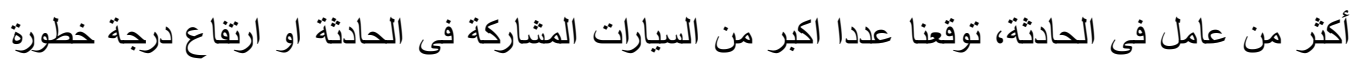

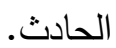

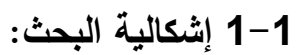

أن الوفيات بسبب حوادث المرور تزايدت حتى بلغت فى بعض الدول مسنويات تفوق الوفاة الطبيعية ،

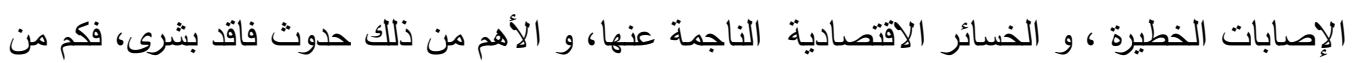

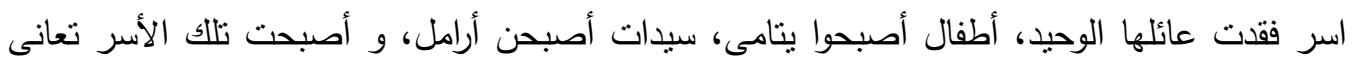
من مشكلات اجتماعية و اقتصادية خطيرة. 
يحاول البحث دراسة المتغيرات المؤثرة فى حوادث المرور ، و أن التركيز على نلك العوامل و إعادة تأهيلها سوف يكون له اثر واضح فى التقليل من حوادث المرور، و بالتالى التقليل من الآثار المترتبة عليها.

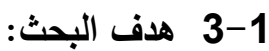

مما سبق تتحدد أهداف الدراسة فى هذا البحث فيما يلى: -

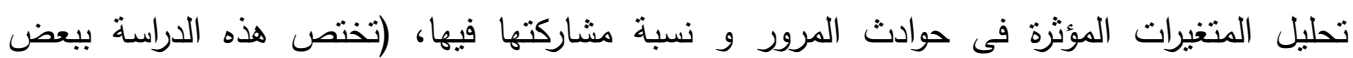
المتغيرات المؤثرة فى حوادث المرور كالإنسان، المكان، الزمان).

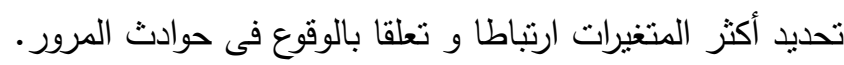

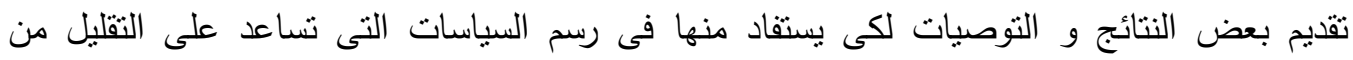
حوادث المرور ، و بالتالى التقليل من الأثار المترتبة عليها. 1-1 - 2 - 1 منهجية البحث: لتحقيق الأهداف السابقة اتبع منهج المسح الميدانى و تحليل البيانات و استتباط الاسباب كأسلوب بحثى، و تم بواسطة تحديد مجموعة خطوات كأساس منهجى لهذه الدراسة: الدراسة و التحليل: من خلال دراسة و تحليل المتغيرات المؤثرة في حوادث المرور و نسبة الدهات المشاركة فيها. الدراسة الميدانية : من خلال تصميم استمارة استبيان و استكمالها فى كل حادثة، و كانت البيانات

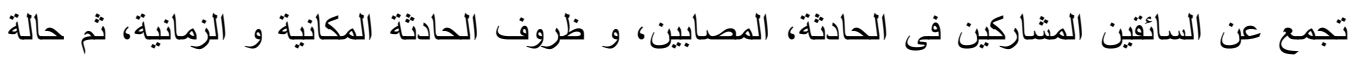
المركبة او المركبات المشاركة فى الحادث. التحليل الاحصائى للبيانات: بعد استكمال الاستمارات نم إدخال بياناتها الى الحاسب الآلى، ولى و تمت معالجتها معالجة إحصائية، و استهدف إجراء التحليل الاحصائى تحديد العلاقات الارتباطية بين المتغيرات. اسنتباط الأسباب التى أدت الى تلك النتائج. النتائج و التوصيات: التوصل الى مجموعة من النتائج، ووضع بعض التون التوصيات التى يستفاد منها فى رسم السياسات التى تساعد على التقليل من حوادث المرور، و بالتالى التقليل من الأثار المثرتبة عليها. 2- إجراءات القيام البحث

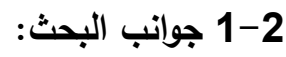
اشتثلت الدراسة على المتغيرات المؤثرة فى حوادث المرور و نسبة المشاركة فيها (تختص هذه الدراسة ببعض المتغيرات المؤثرة فى حوادث المرور كالإنسان، المكان، الزمان). 
2-2

تم تصميم استمارة استنيان يقوم احد المساعدون بنطبيقها حين وقوع الحادثة (على الطريق او فى قسم

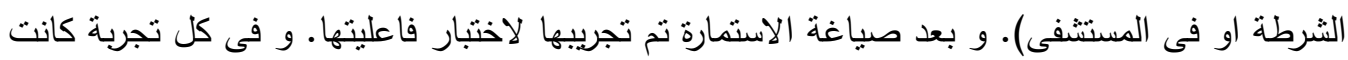

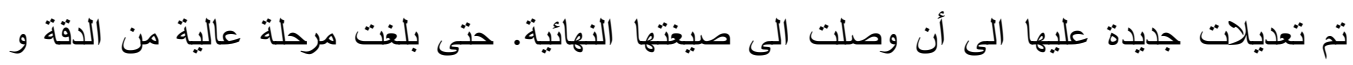

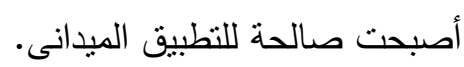
3-2

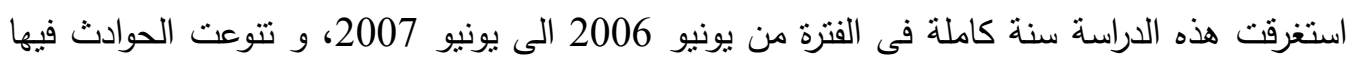

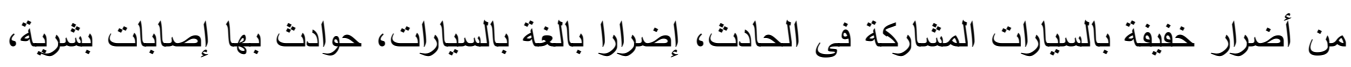
او حوادث وفاة.

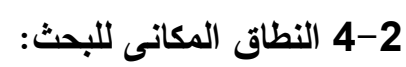

نم اختبار المدن الأكثر ازدحاما من حيث حركة المرور فيها و من ثم فمن المتوقع ان تكون النسبة

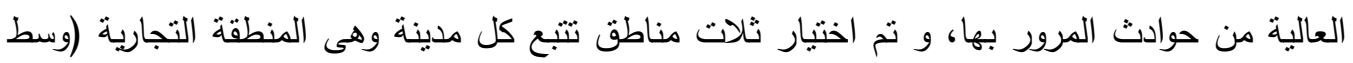

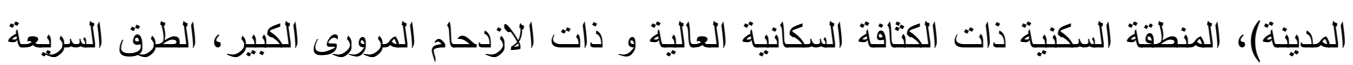

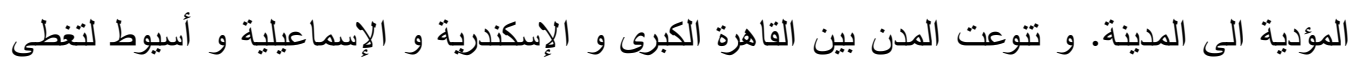

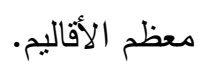

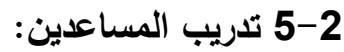

نم تدريب المساعدين على أسلوب ملء الاستمارة فى كل حادثة، و كانت البيانات تجمع عن السائقين

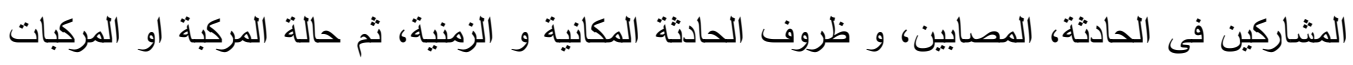
المشاركة فى الحادث. 2-6 التحليل الاحصائى للبيانات: بعد استكمال الاستمارات فى الفترة من يونيو 2006 الى يونيو 2007 توقف العمل الميدانى للبحث، ثم

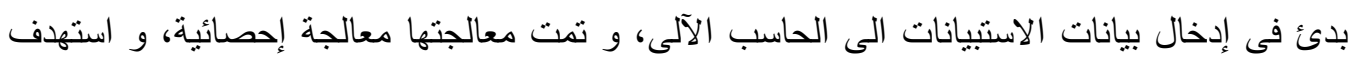
اجراء التحليل الاحصائى تحديد العلاقات الارتباطية بين المتغيرات.

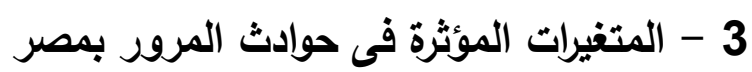
هناك مجموعة من العوامل التى تشارك معا فى حوادث المرور، و يمكن تصنيف تلك المتغيرات من

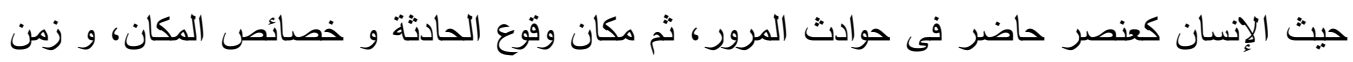

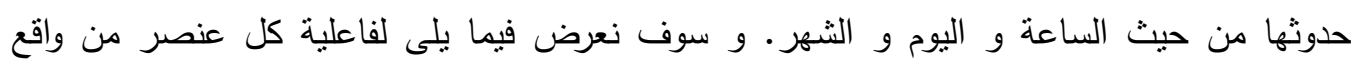
معطيات الدراسة الميدانية للبحث. 
3-1-3 الإنسان كعنصر حاضر فى حوادث المرور.

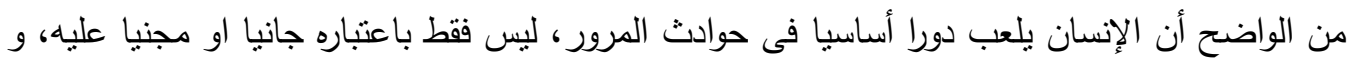

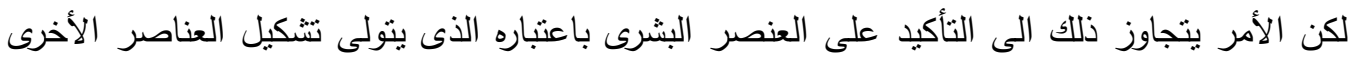

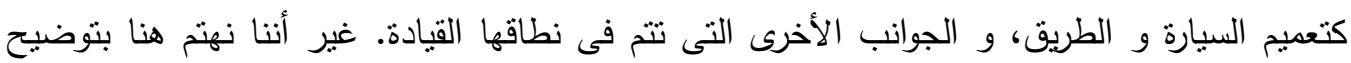

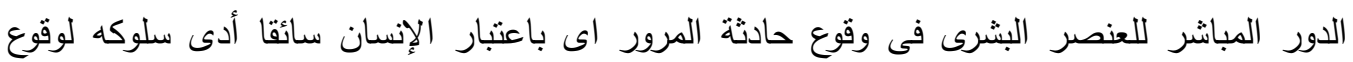

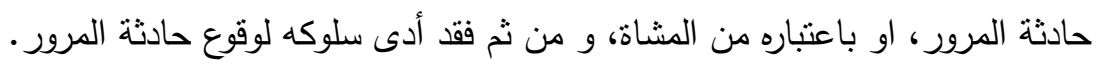

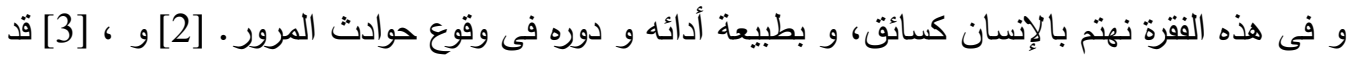

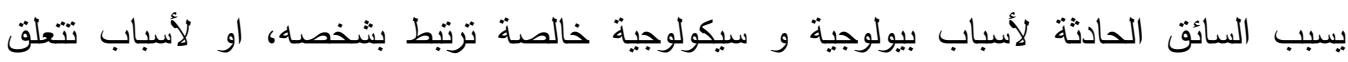

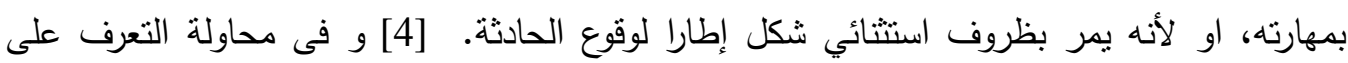

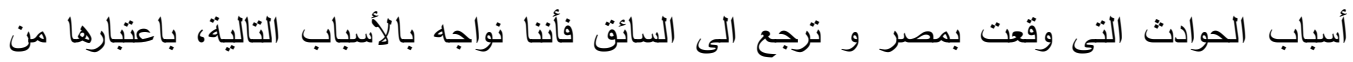

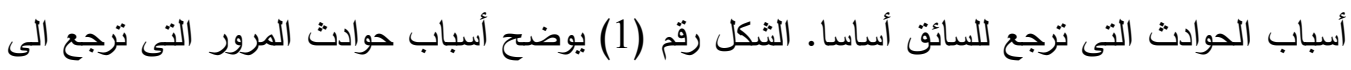

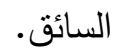

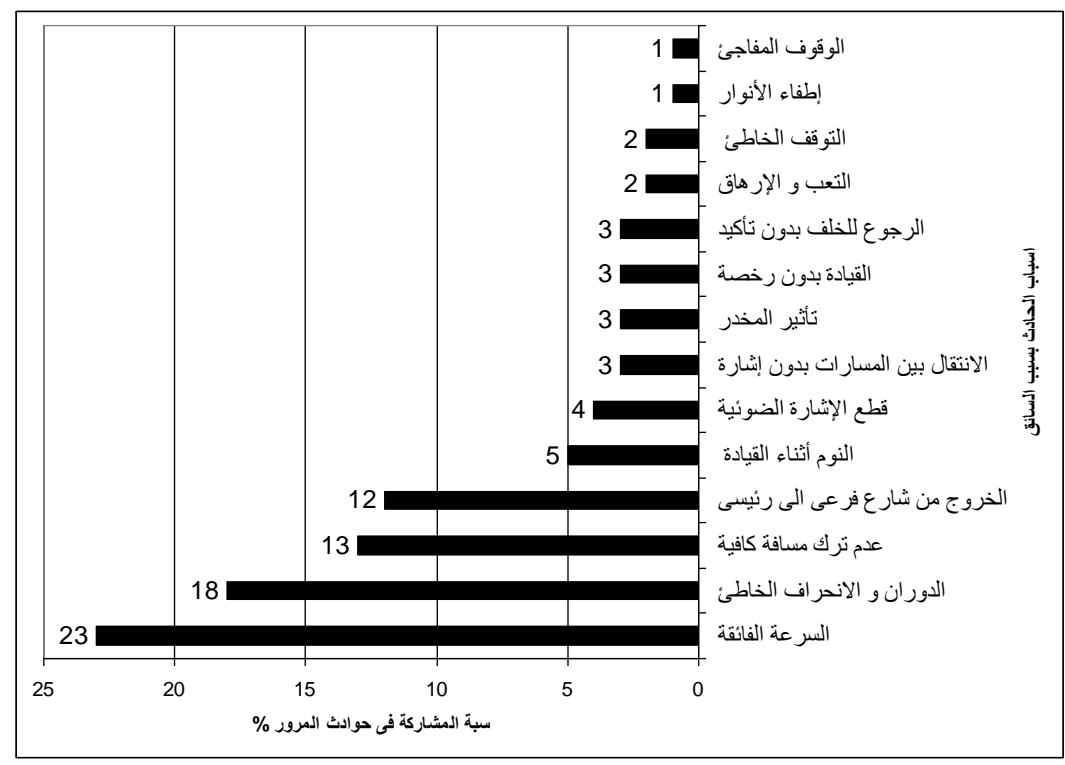

الثكل رقم (1) يوضح أسباب حوادث المرور التى ترجع الى السائق

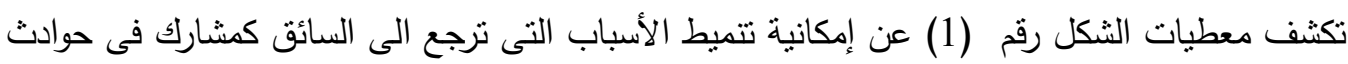
المرور الى أربعة أنماط، يتمنل النمط الأول فى مجموعة الأسباب المنصلة بالطبيعة الفيزيقية للسائق و يدخل فى إطار ذلك التعب و الإرهاق حيث شارك هذا العامل بنسبة 2 \% من الحوادث. إن الإرهاق

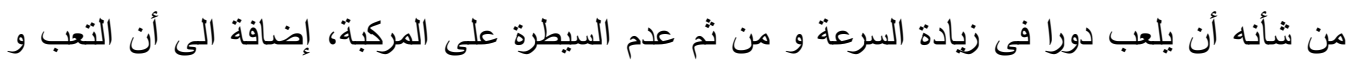
الإرهاق من شأنه ان يقلل قدرة الإنسان على مراعاة قواعد العاد المرور او قواعد التعامل مع المركبة ذاتها 
الأمر الذى يزيد من احتمالية وقوع الحادثة. [5] و يتمثل العامل الثانى فى النوم أثثاء القيادة حيث تسبب فى وقوع نسبة 5 \% من الحوادث، ذلك يعنى أن العوامل المتصلة بالحالة الفيزيقية للسائق لعبت دورها بنسبة 7 \% من حوادث المرور بالدراسة.

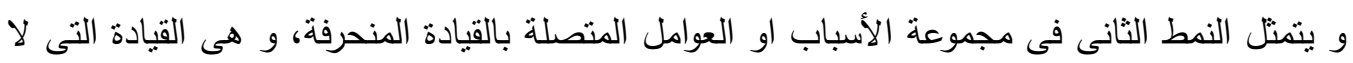

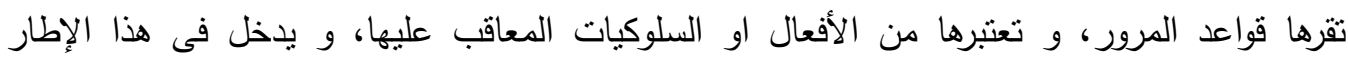

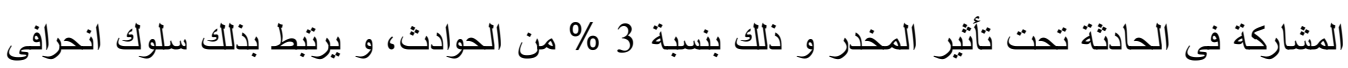

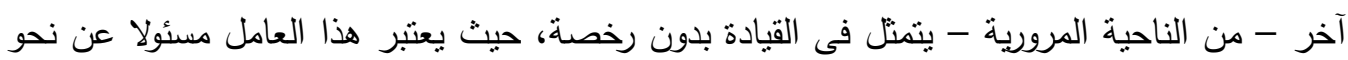
3 \% من الحوادث المرورية. و القيادة تحت تأثثر المخدر تؤدى الى عدم إدراك مكونات الإطار او

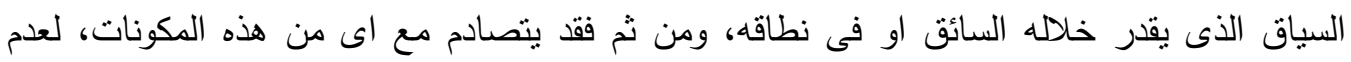

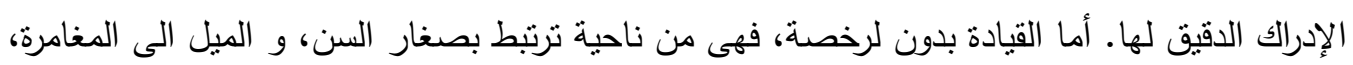

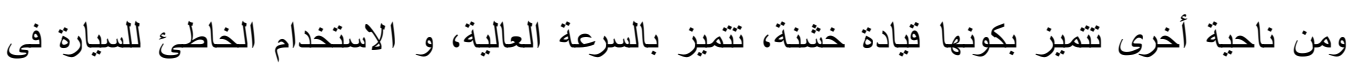

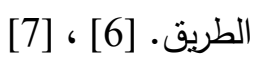

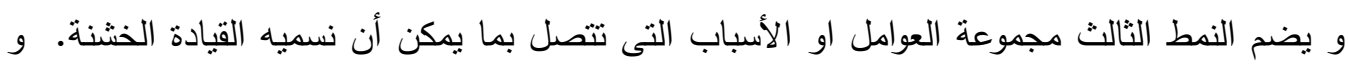
من ذلك السرعة الفائقة حيث نسببت فى وقوع حوادث مرور بنسبة 23 \% وهى الفى نسبة عالية للغاية، و ذللك لأن السرعة الفائقة من شأنها أن تقفد السائق القدرة الكاملة على التحكم فى مركبته إضافة الى أنها تضعف قدرته على التحكم فى المتغيرات النى يقود فى إطارها، لأنها تقلل الفاصل بين أداراك المتغير و

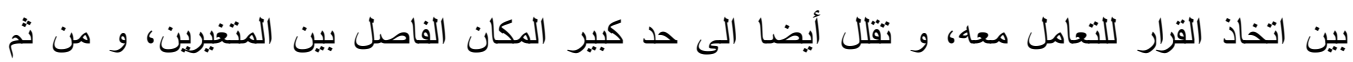

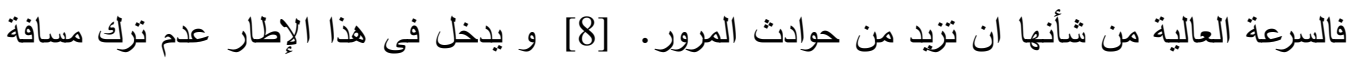
كافية بين السيارات و هو العامل الذى تسبب فى نسبة 13 \% من حوادث المرور، و و ذللك لأنه يماتل

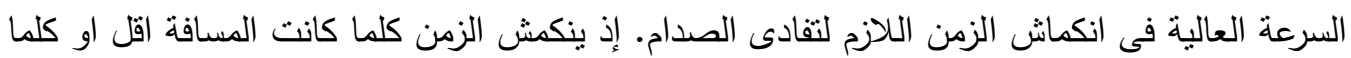

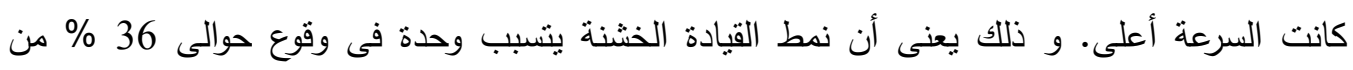

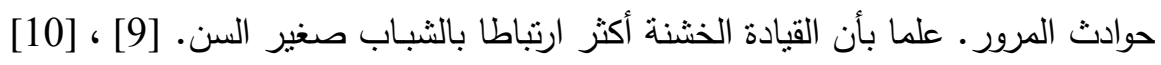

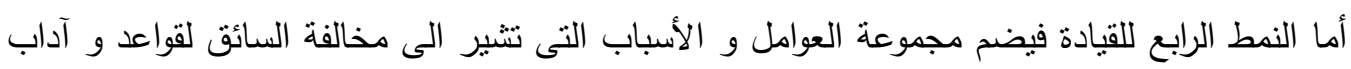
المرور، و يدخل فيها النوقف الخاطئ الذى تسبب فى وقوع 2 \% من الحوادث، الدوران و الانحراف

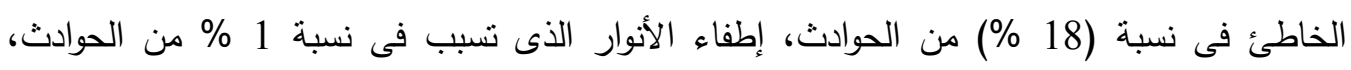
الوقوف المفاجئ الذى نسبب فى نسبة 1 \% من الحوادث، الانتقال بين المسارات بدون إثنارة و نسبب

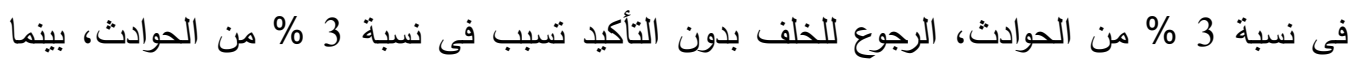

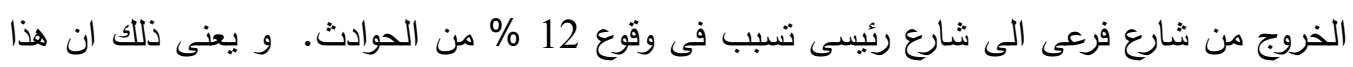

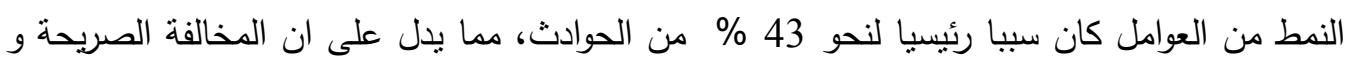


الواضحة لبعض قواعد المرور تسبب فى هذا الكم الهائل من الحوادث. و هذا النمط و نمط القيادة

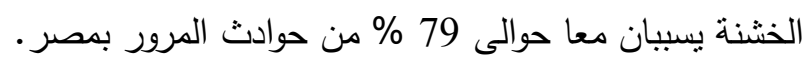

و بعد أن تحدثا عن العنصر البشرى المشارك فى حوادث المرور باعتباره سائقا لمركبة، بغض النظر

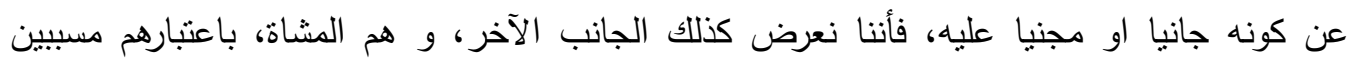
لحوادث المرور، و الثكل رقم (2) يوضح أسباب الحوادث التى ترجع الى المشاة.

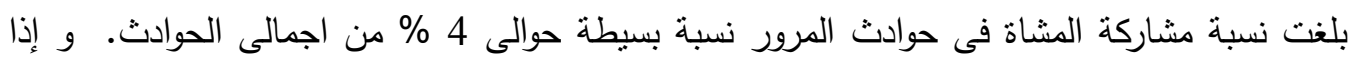

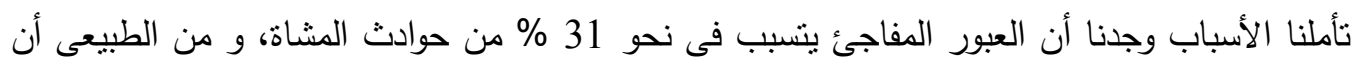

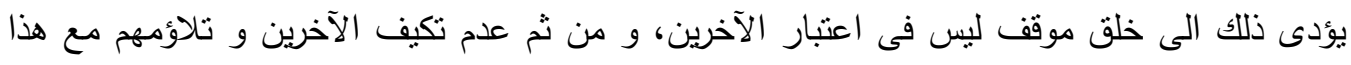

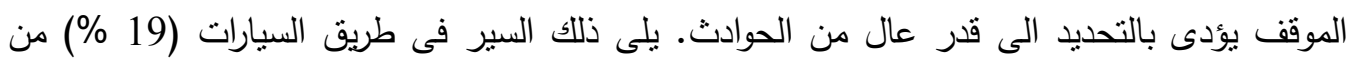
حوادث المشاة، نظرا لانسيابية السيارات و خاصة فى الطرق الرئيسية داخل المدينة، مما يتيح درجة لئل

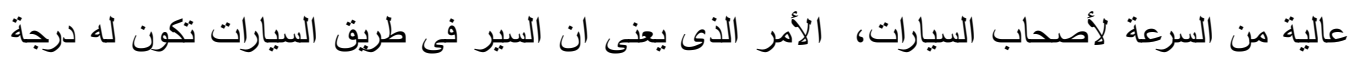

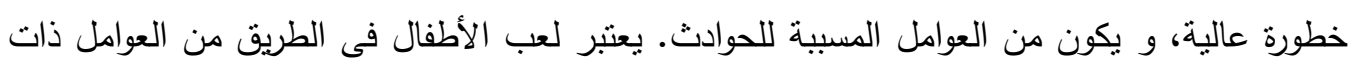

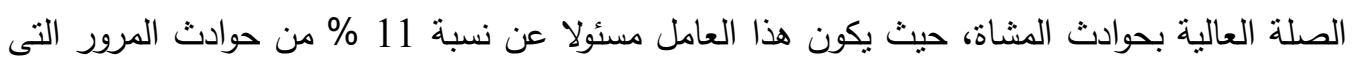
يسببها المشاة. و يعتبر السبر عكس الاتجاه من العوامل المسببة للحوادث بسبب المشاة، حيث يساهم لهاهية هذا العامل بنحو 9 \% من حوادث المرور التى بسببها المشاة و ذلك لأنه يخلق تتاقضا فى الاتجاه

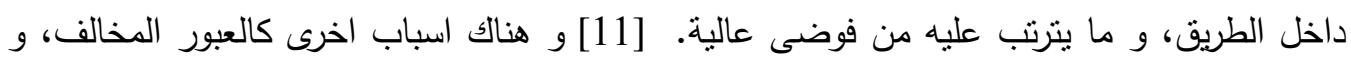

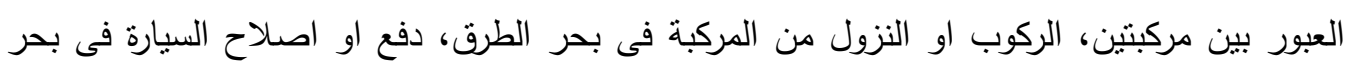

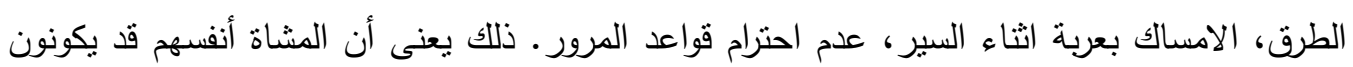
هم المسئولين عن وقوع كثير من حوادث المرور . 


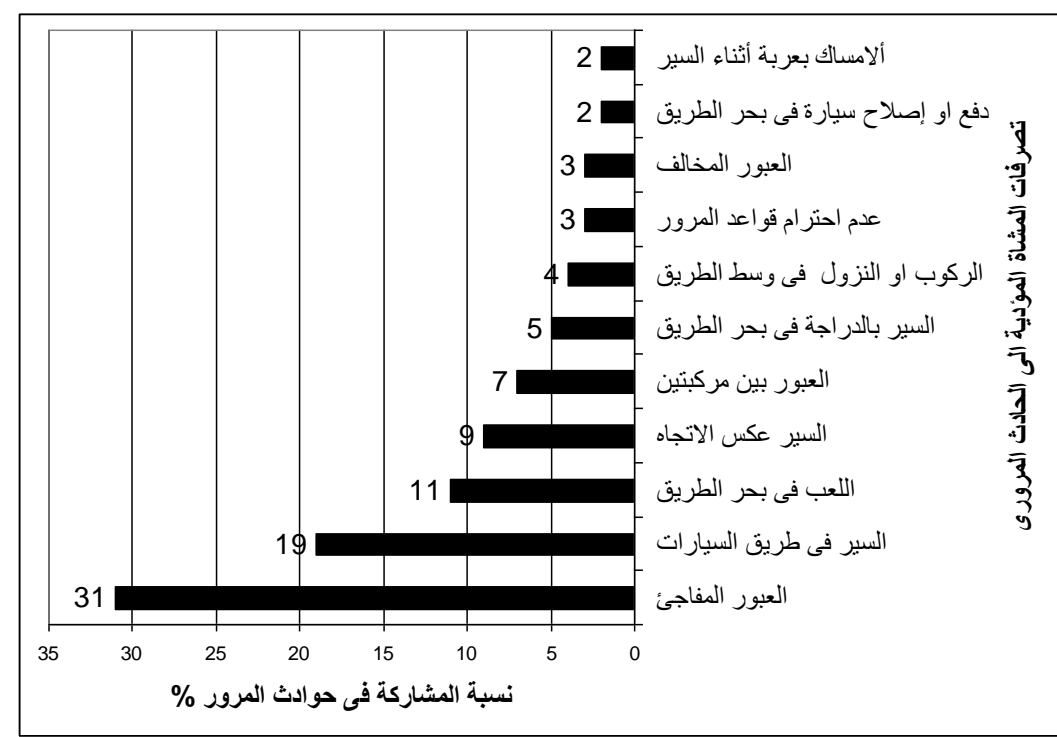

الثكل رقم (2) يوضح أسباب حوادث المرور التى ثرجع الى المشاة

$$
\text { 3-2 حوادث المرور - المنطقة و المكان }
$$

يعتبر مكان وقوع الحادث من المتغيرات الهامة المسببة لحوادث المرور ، و يتدرج المكان من كونه منطقة

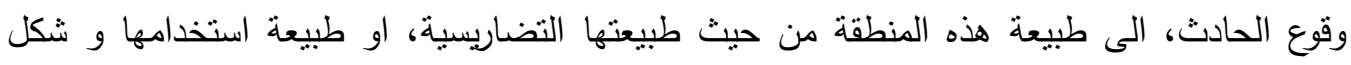

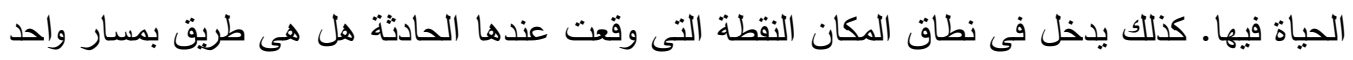

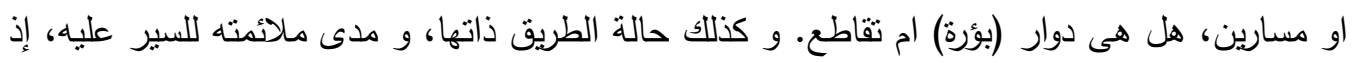
يعتبر هو الآخر من العناصر التى لها دورها فى وقوع حادثة المرور .

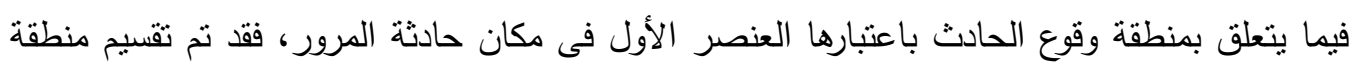

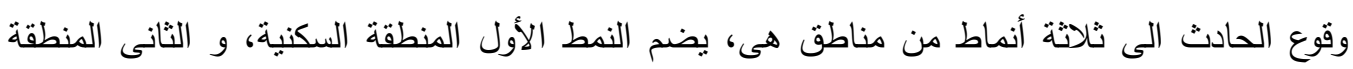
التجارية، و الثالث خارج المدينة على الطرق السريعة. و المنطقة السكنية هى المنطقة النى يقطن بها السكان، و اختيرت المنطقة السكنية ذات الكثافة السكانية

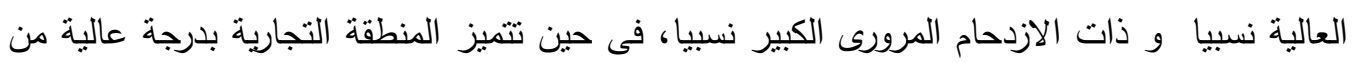

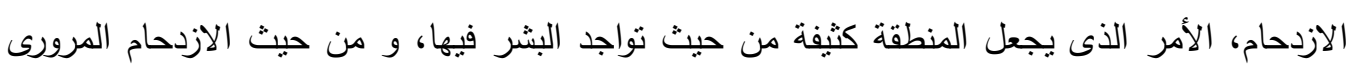

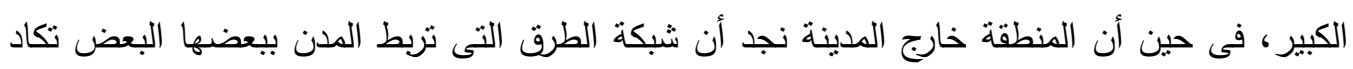

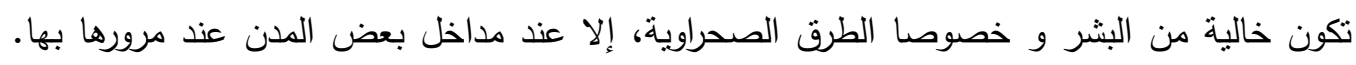
شكل رقم (3) يوضح توزيع حوادث المرور طبقا لأنماط المناطق بالمدينة و خارجها. 


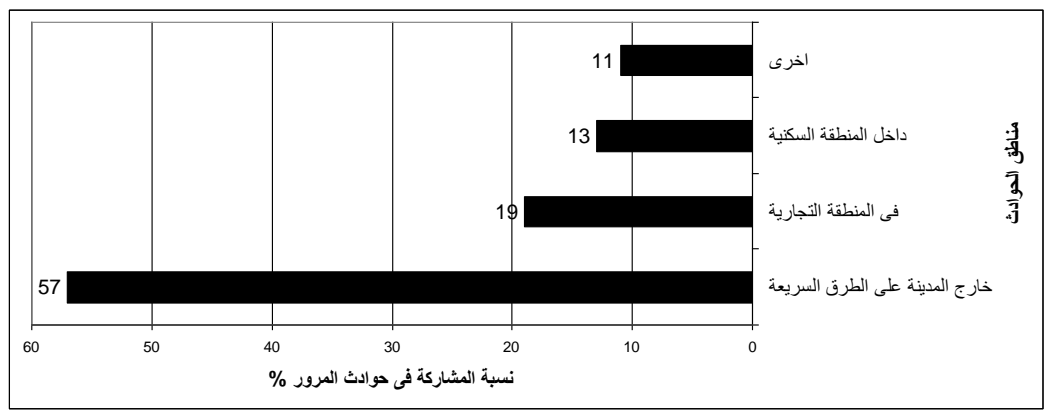

شكل رقم (3) يوضح توزيع حوادث المرور طبقا لأنماط المناطق بالمدينة و خارجها

المنطقة السكنية: و فيها من المدكن أن يلعب الأطفال أمام البيت، و أن بركبوا الدراجات الهوائية او

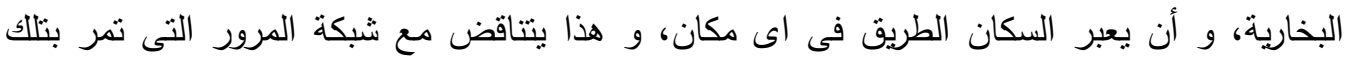

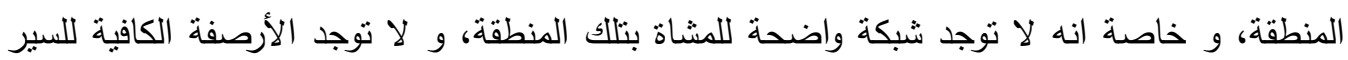

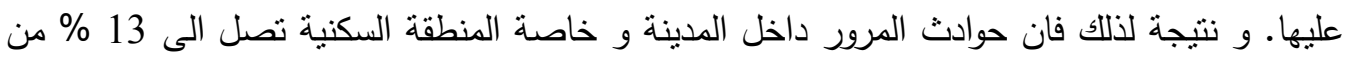
حوادث المرور •

جاءت نسبة المشاركة فى حوادث المرور خارج المدينة على الطرق السريعة حوالى 57 \% و و لكن فى الكى

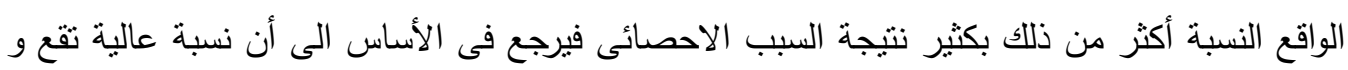

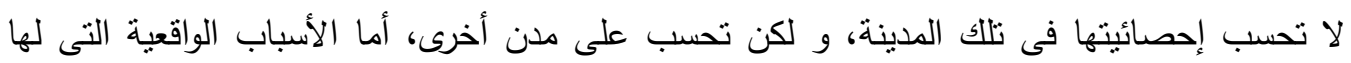

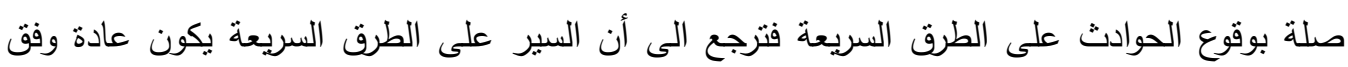

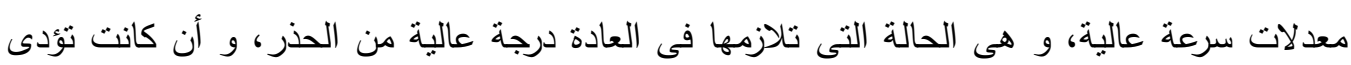

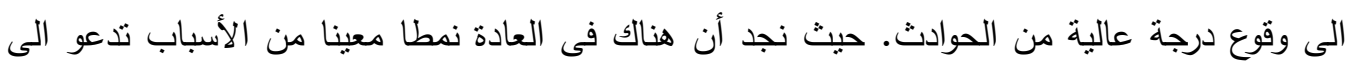

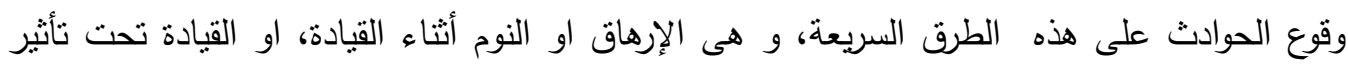

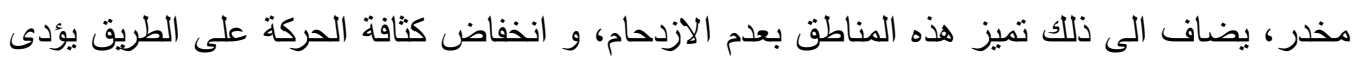

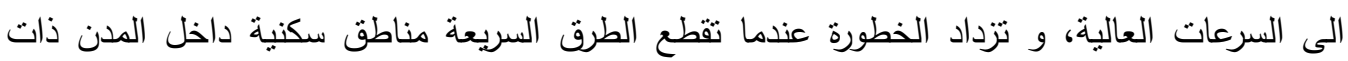

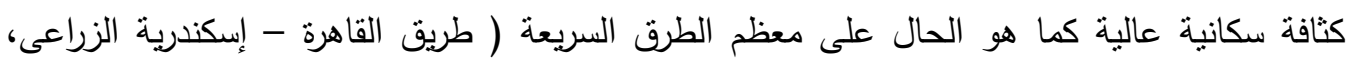
طريق الصعيد الزراعى). و معظم الحوادث على الطريق السريعة من النوع القاتل نظرا للسرعات العالية،

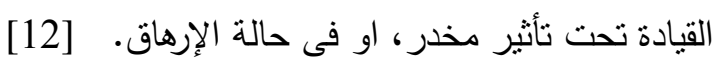
المنطقة التجارية بوسط المدينة تعتبر من اعلى الكثافات السكانية بالمدينة، و من اعلى كثافات المرور

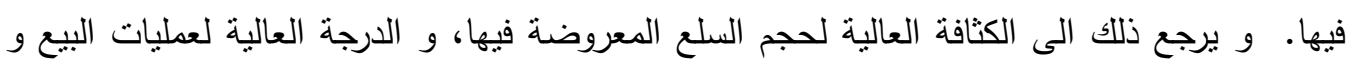

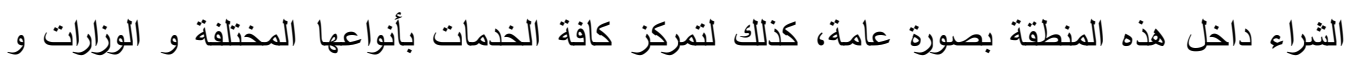

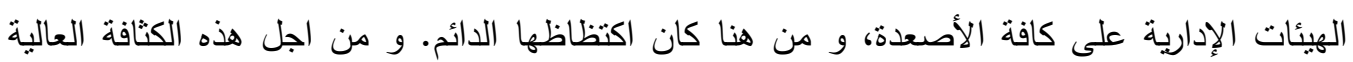


للبشر و السيارات - ضيق المكان - نجد أن المرور بطئ للغاية فى تلك المنطقة، و قواعد السير فيها

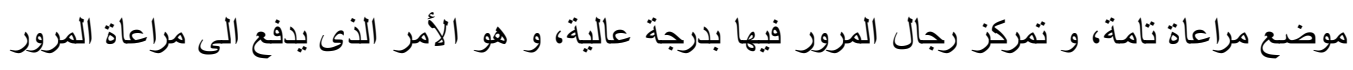

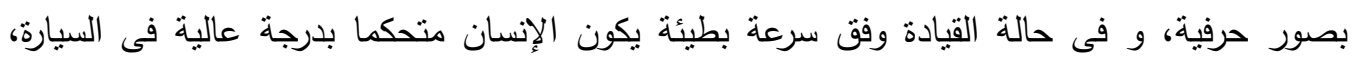
الأمر الذى يؤدى الى انخفاض نسبة الحوادث او تلاقيها من الناحية النظرية. و لكن نظرا لأل الستخدام

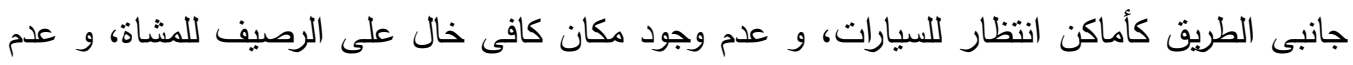

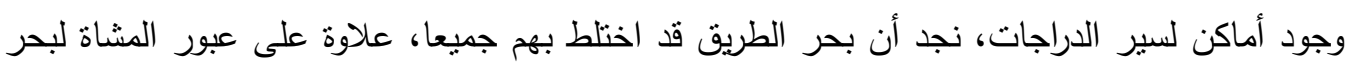

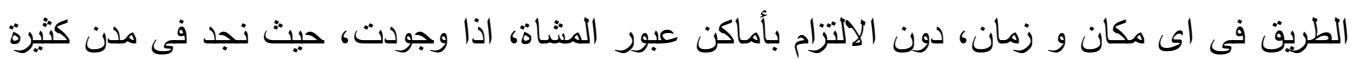

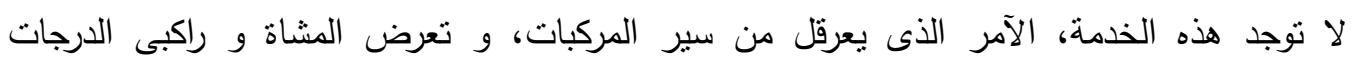

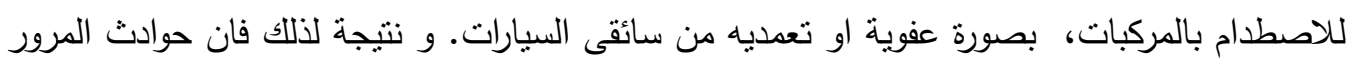

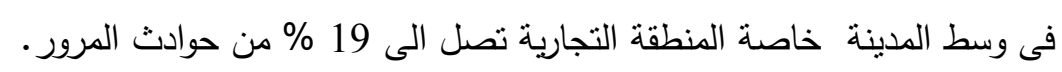

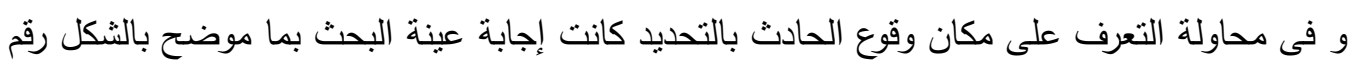

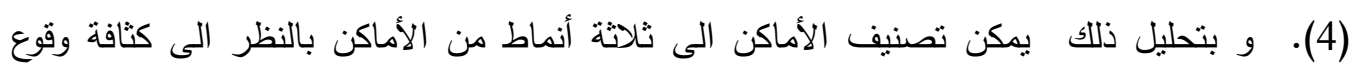

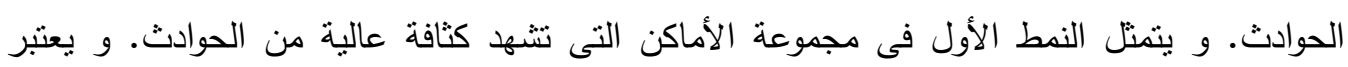

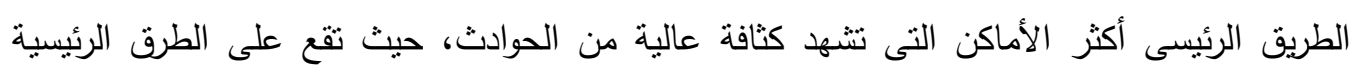

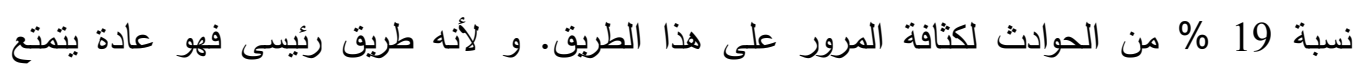

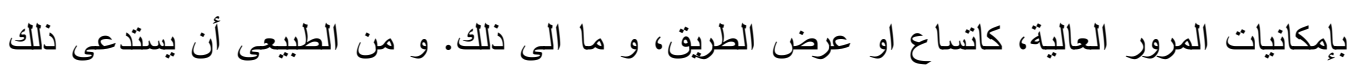

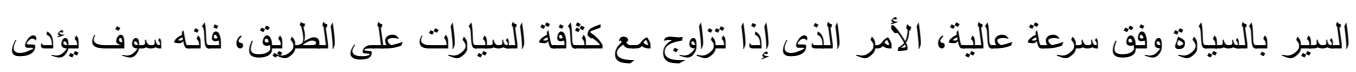

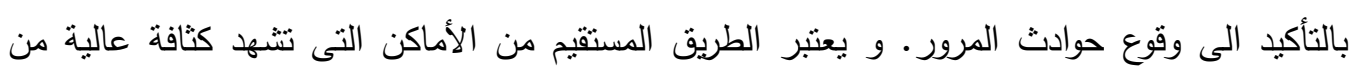

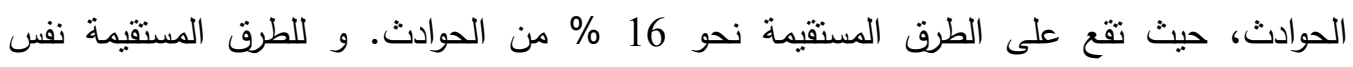
خصائص الطرق الرئيسية التى تساعد على وقوع معدلات عالية من الحوادث، وهى الكثافة العالية

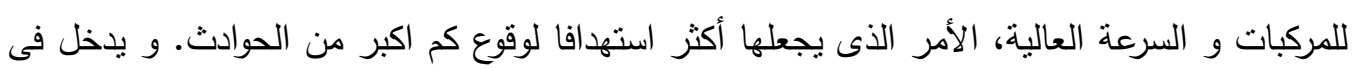
إطار هذا النمط الطريق ذو المسارين فأكثر، حيث نجد هذا النمط من الطرق يشهد كثافة نسبية من

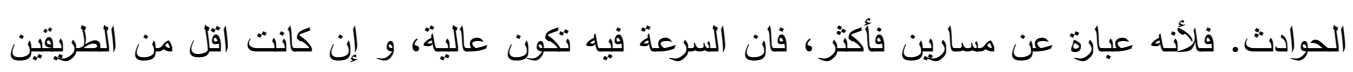

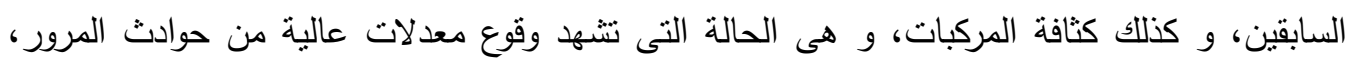
حيث يثهد نسبة تصل الى 13 \%. و و هو ما يعنى أن حوادث هذا النمط من الأماكن تشهي معدلات عالية لاعتبارين: كثافة عدد المركبات التى يتعايش وجودها فى هذه الأماكن إضافة الى السرعة العالى العالية

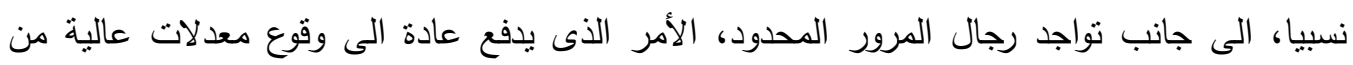
الحوادث. 
و النمط الثانى يضم الأماكن التى نتهر مستوى متوسطا من الحوادث بالنظر الى النمط الأول. و يضم

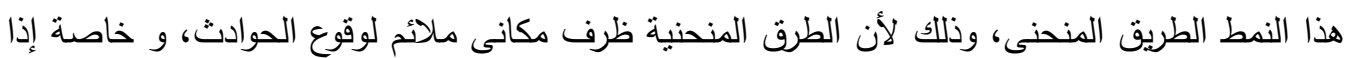

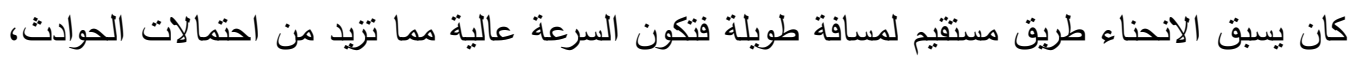

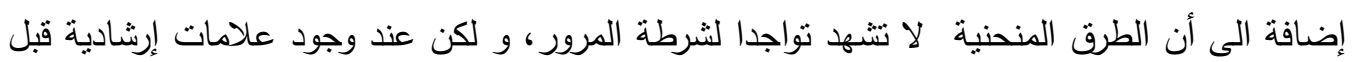
الانحناء بمسافة كافية، تؤدى الى تتبيه السائق و بالتالى القيادة بسرعة منخفضة عند الاتحناء، و زيادة

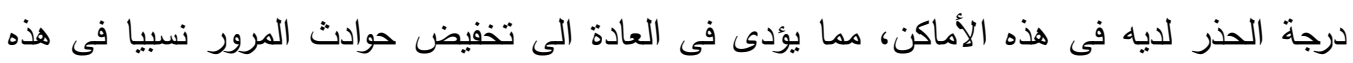

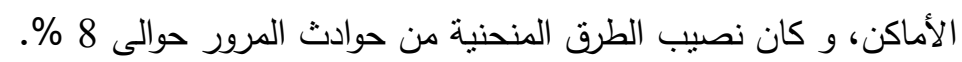

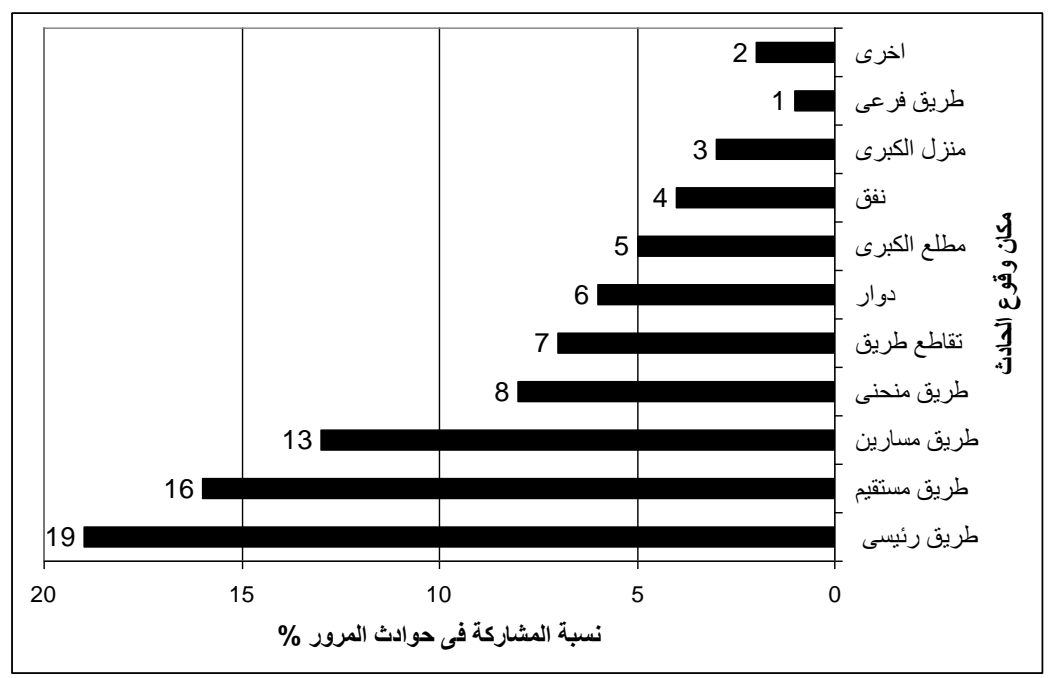

شكل رقم (4) توزيع حوادث المرور بالنظر الى مكان وقوع الحادث

و يعتبر تقاطع الطرق من الأماكن التى تشهد معدلات حوادث متوسطة، وذللك لأن التقاطع ظرف مكانى

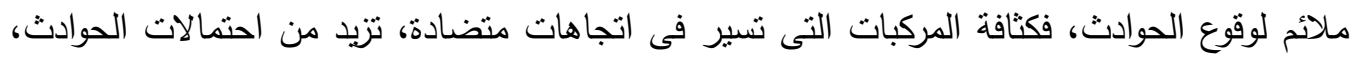

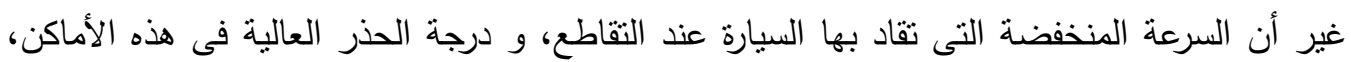

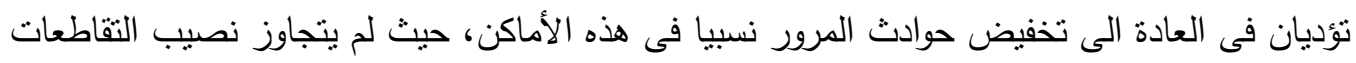

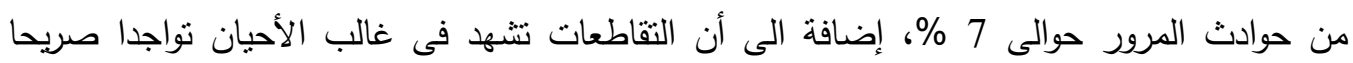

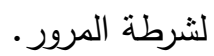

و يعتبر الدوار (البؤرة) هو الدكان الثالث فى هذا النمط الذى يشهد درجة متوسطة من حوادث المرور،

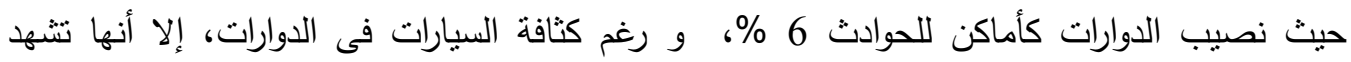

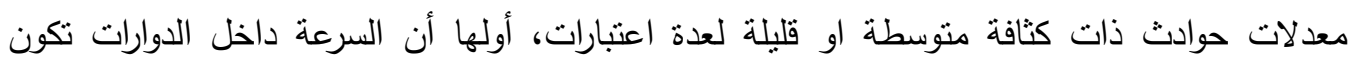

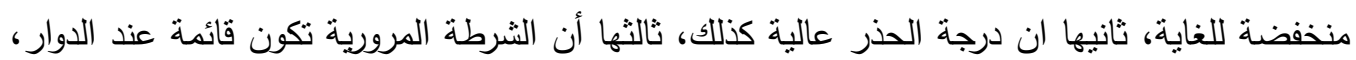


و لذلك تتخفض نسبة الحوادث نسبيا فى الدوارات بعد أن كان من المنوقع أن تكون عالية بحكم طبيعة الدوارات كعنصر فى بناء المرور للمدينة.

و يدخل فى النمط الثالث مجموعة الأماكن التى تشهد معدلات منخفضة من حوادث المرور نسبيا،

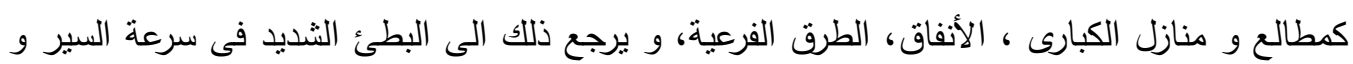
درجة الحذر العالية فى تلاك الأماكن. و بذلك فان مكانا معينا يشهد درجة عالية او منخفضة من حوادث المرور بالنظر الى الاعنبارات التالية:

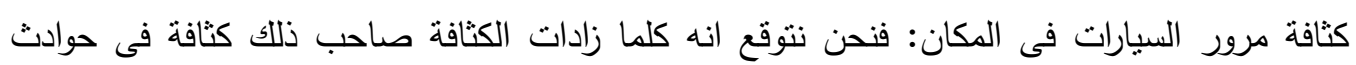
المرور، مع افتراض ثبات العوامل الأخرى. درجة السرعة العالية: حيث انه كلما أتاح المكان درجة سرعة عالية، زاتئ زادت احتمالية وقوع نسبة عالية من

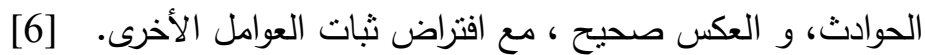

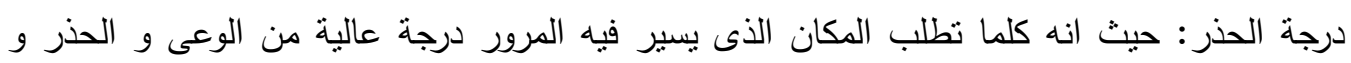

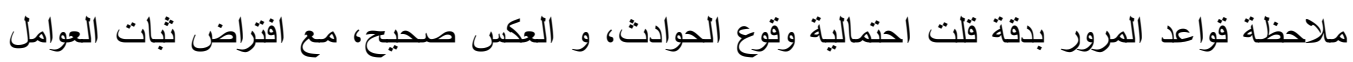

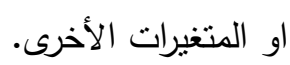

و لما كان الطريق يعتبر أكثر وحدات الدكان بروزا و أهميه لأنه يثكل النطاق الرئيسى الذى تتساب فيه

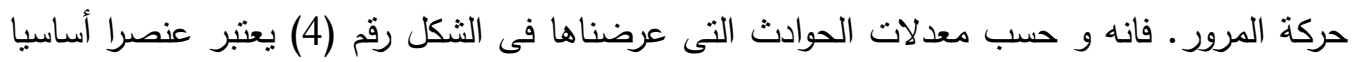

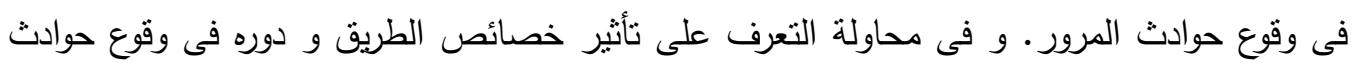

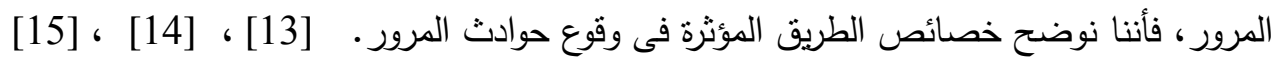

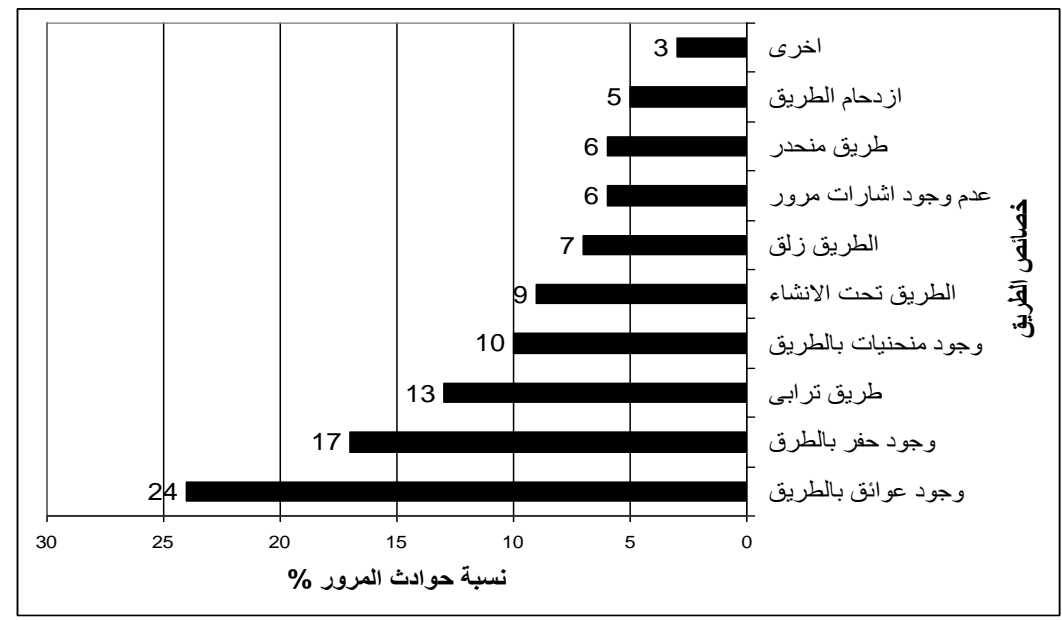

شكل رقم (5) يوضح خصائص الطريق المؤثزة فى وقوع حوادث المرور

و من تحليل الثكل رقم (5) يتضح لنا مجموعة من الحقائق، لعل أولها و أبرزها وجود عوائق بودئ بالطريق حيث تسبب ذللك فى وقوع نسبة 24 \% من الحوادث التى وقعت على الطرق، و فى العادة لا يكون 
السائق قد أدرك عائق الطريق بالمسافة الكافية لتجنبه. أما بسبب عوائق تمنع او تقلل الروئة او موانع

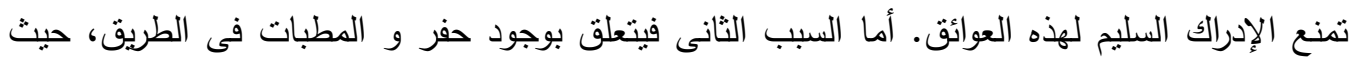

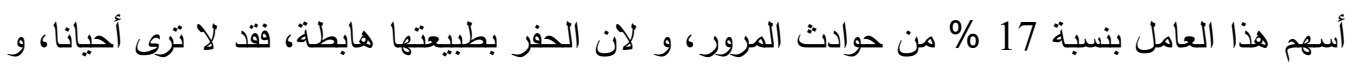

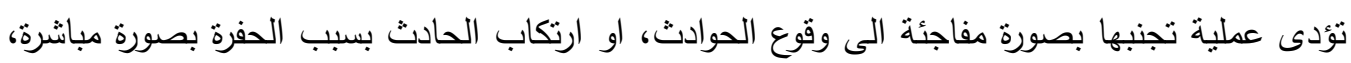

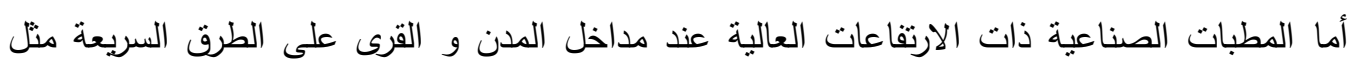

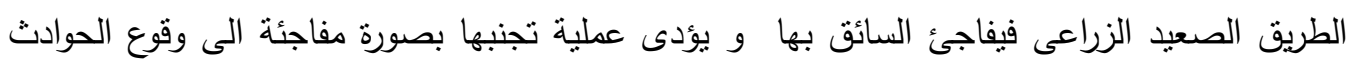

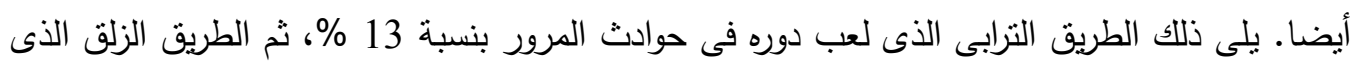
يلعب دوره فى حوادث المرور بنسبة 7 \%،حيث تقلل من قدرة السائق على التحكم فى السيارة و القيادة

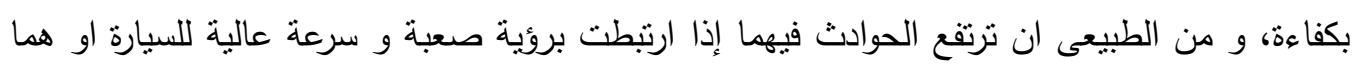

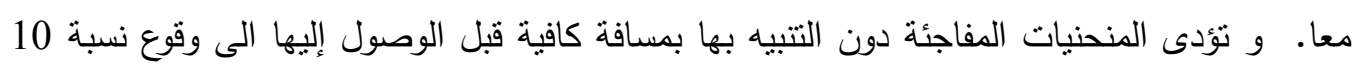

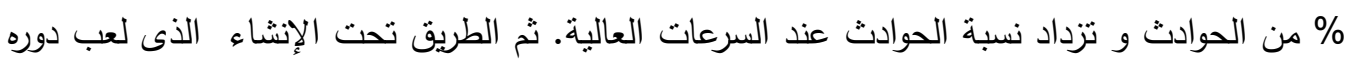
بنسبة 9 \%، نظرا لوجود بعض العوائق فيه. كذلك عدم وجود إثنارات مرور لتنظيم حركة المرور ، و قد قد لعبت دورها بنسبة 6 \% من الحوادث. ثم الطريق المنحدر الذى لعب دوره بنسبة 6 \% بـ كذلك الطرق

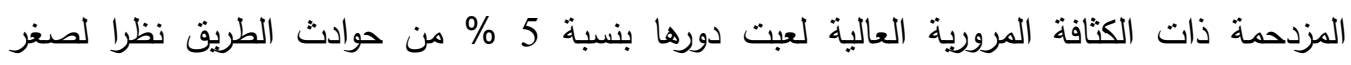

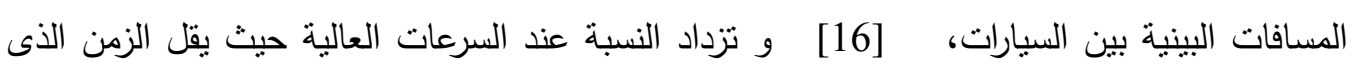
يمكن معه السائق للتحكم فى السيارة و كلما قل الزمن اللازم لذلك كلما زادت نسبة الحوادث. 3- 3 توزيع حوادث المرور بالنظر الى متغير الزمان

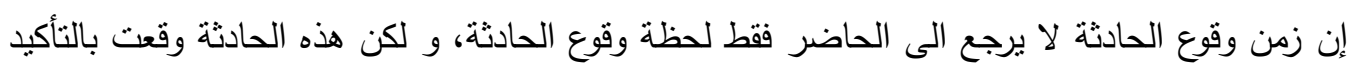

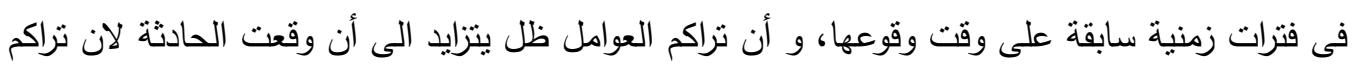

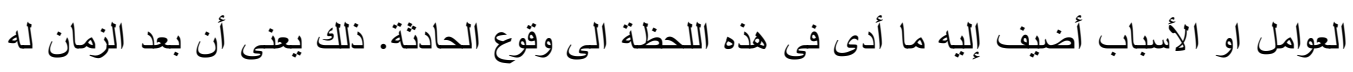

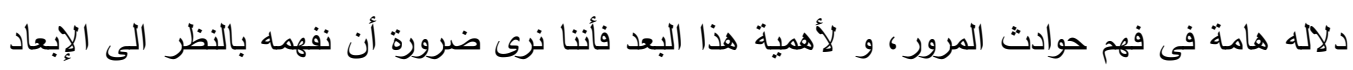

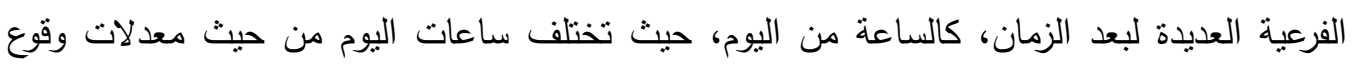
الحوادث فى إطارها، و كذللك اليوم من الأسبوع او اليوم من الثهر، لان لان لذاعلك بالتأكيد دلالته الاجتماعية

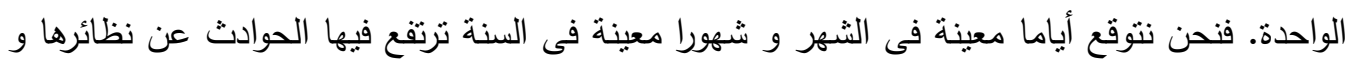

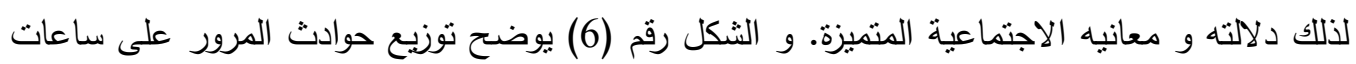
اليوم. و تكثف قراءة معطيات الثكل رقم (6) عن مجموعة من الملاحظات الأساسية. 


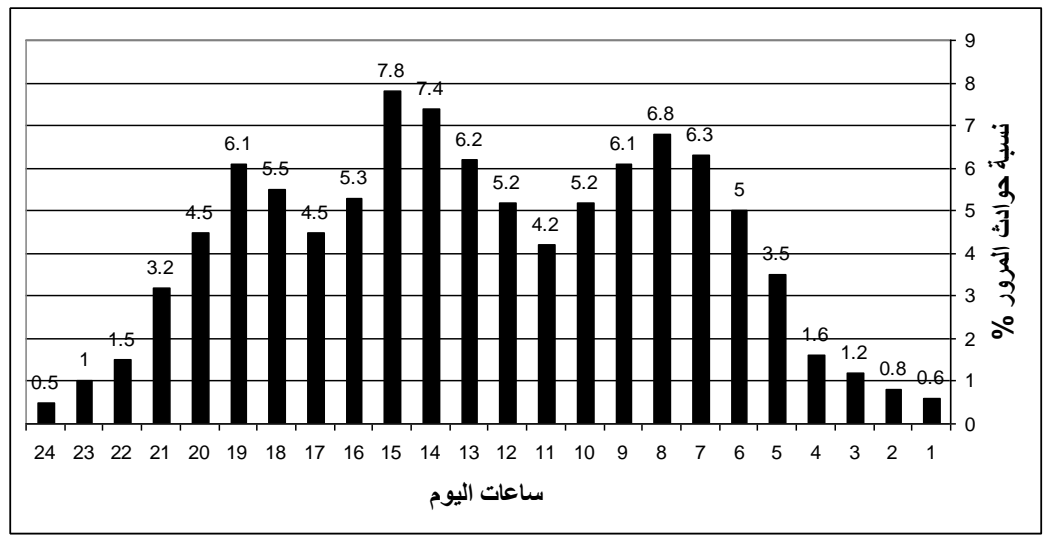

الثكل رقم (6) يوضح توزيع نسبة حوادث المرور على ساعات اليوم.

تتمثل أول ملاحظة فى وجود علاقة بين حجم التفاعل القائم فى كل ساعة من ساعات اليوم، و بين

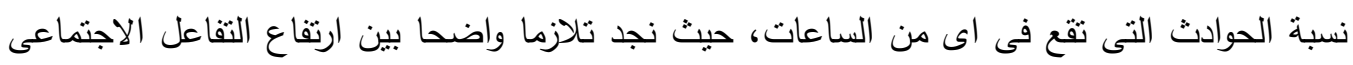

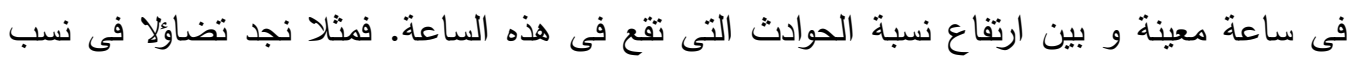

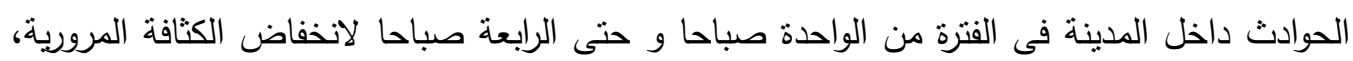

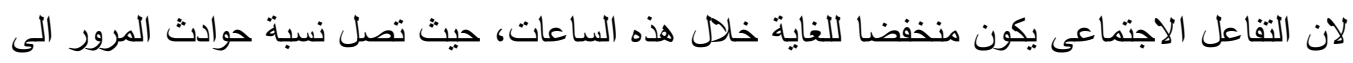

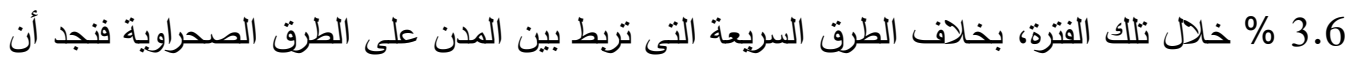

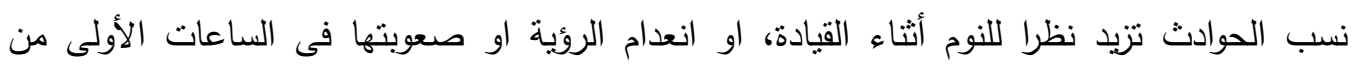

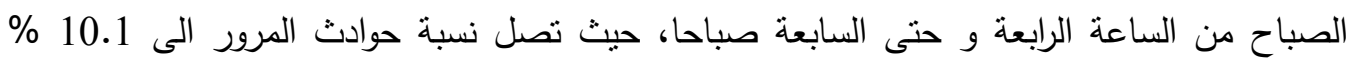

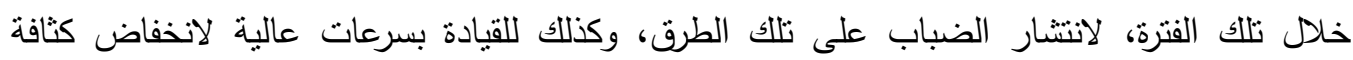
المرور على تلاك الطرق فى تلك الفترة.

و تتمثل الملاحظة الثانية فى وجود فترتين ترتفع فيهما حوادث المرور، تتمثل الفترة الأولى من الساعة

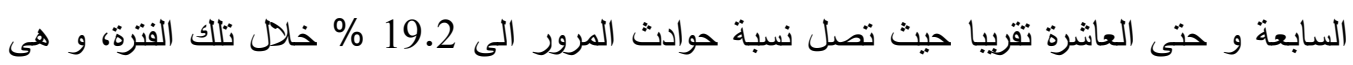

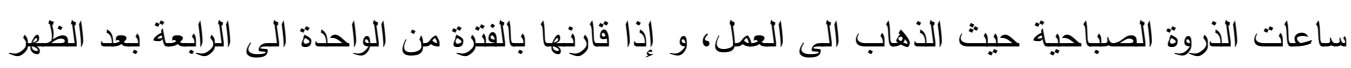

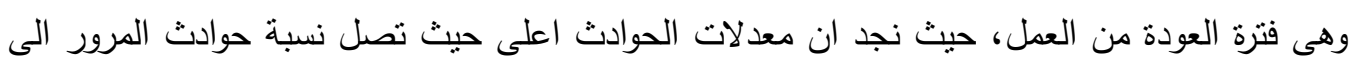

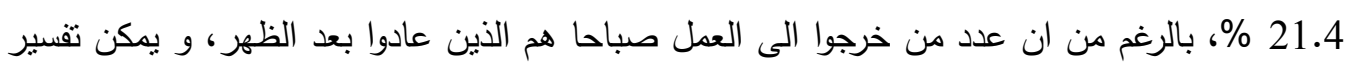

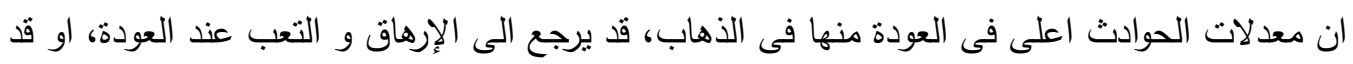

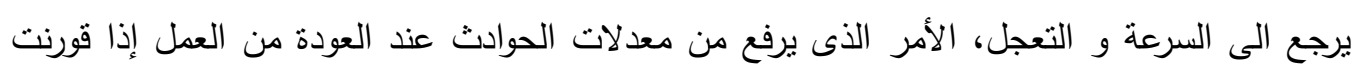
بمعدلاتها عند مغادرة المنزل ذهابا الى العمل.

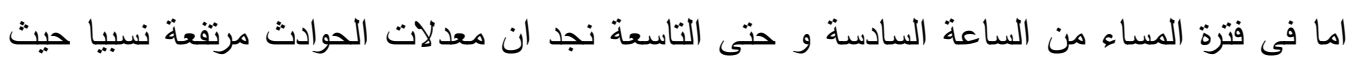
تصل نسبة حوادث المرور الى 16.1 \%؛ حيث الكثافة المرورية العالية لأداء الأنشطة الاجتماعية، 
التسويقية، التزفيهية، خلافه. فى حين تتميز العودة من الخارج الى المنزل، من الساعة التاسعة الى الثانية عشرة، بكونها ذات معدلات منخفضة نسبيا، حيث نصل نسبة حوادث المرور الى 5.7 \%، و ذلك لان فترة العودة الى المنزل طويلة نسبيا.

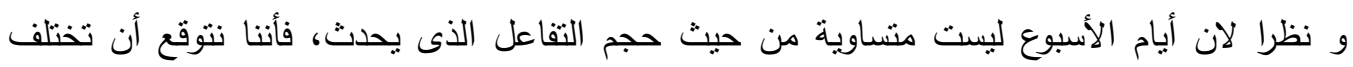

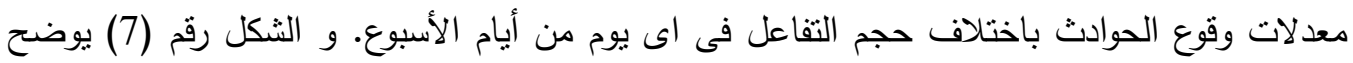
توزيع وقوع الحوادث بالنظر الى أيام الأسبوع.

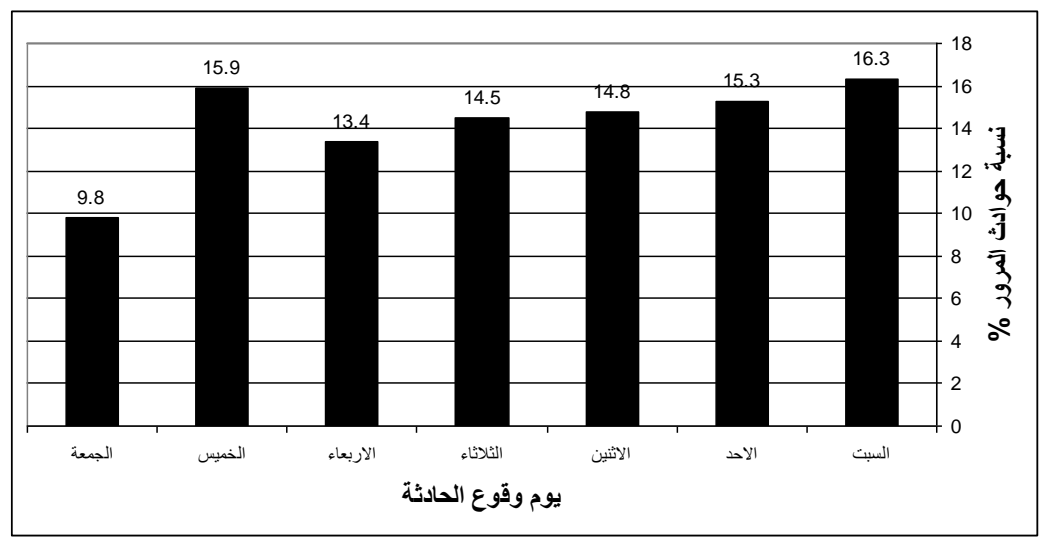

شكل رقم (7) يوضح نوزيع وقوع الحوادث بالنظر الى أيام الأسبوع.

وتكثف قراءة الثكل عن مجموعة من الملاحظات. نجد ان نسبة الحوادث بلغت ذروتها يومى السبت و

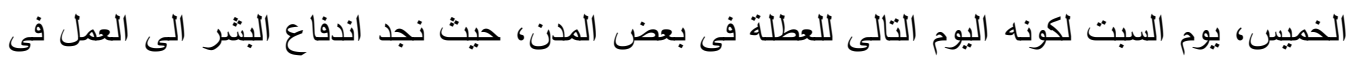

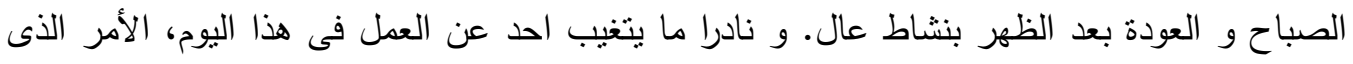
يجعل معدلات الحوادث عالية، حيث تصل نسبة حوادث المرور الى 16.3 \% في هذا اليوم، ثم يبدأ الاندفاع يقل تدريجيا حتى يوم الأربعاء، و يوم الخميس تبدأ معدلات الحوادث فى الارتفاع نظرا للكثافة

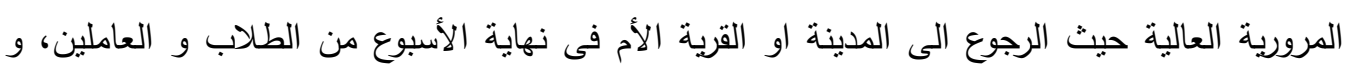

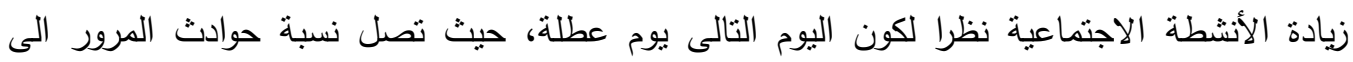
15.9 \% فى هذا اليوم. على خلاف يوم الجمعة الذى تتخفض فيه حوادث المرور الى الى ادنى مستوياتها، تصل نسبة حوادث المرور الى 9.8 \% فى هذا اليوم.

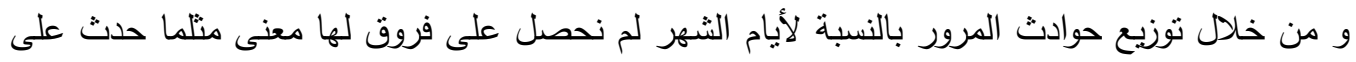

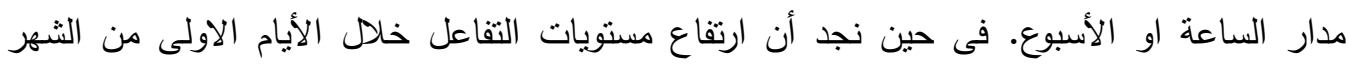

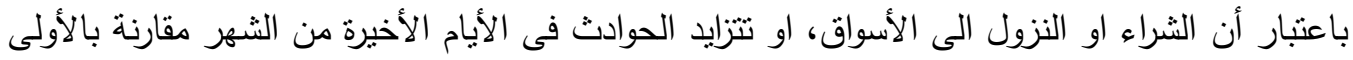

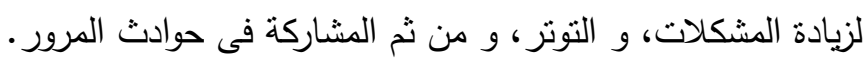


و بافتراض أن شهور السنة تختلف عن بعضها البعض من حيث حجم التفاعل الذى يحدث فى كل

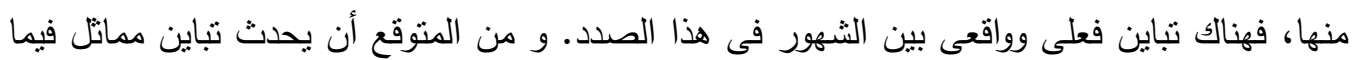

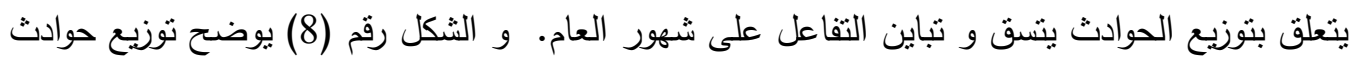

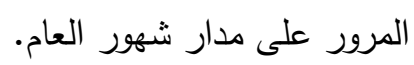
يشهد شهرى سبتمبر و أكتوبر ارتفاعا ملحوظا لحوادث المرور حيث بلغت نسبة المشاركة فى سبتمبر

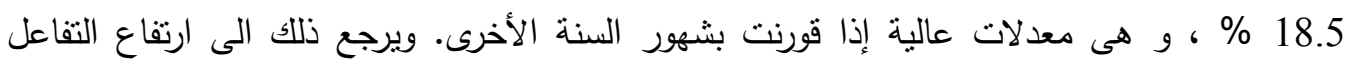

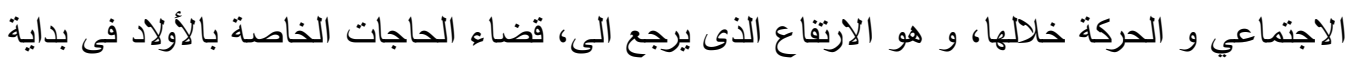

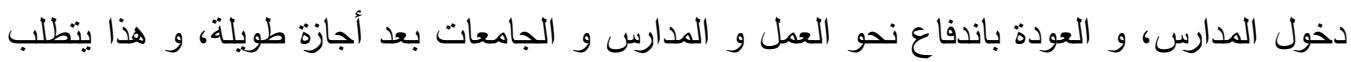

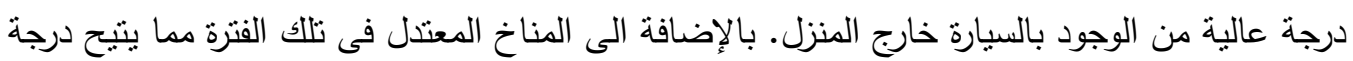

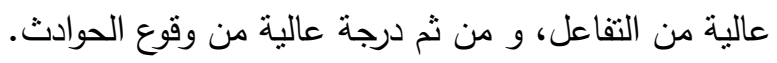

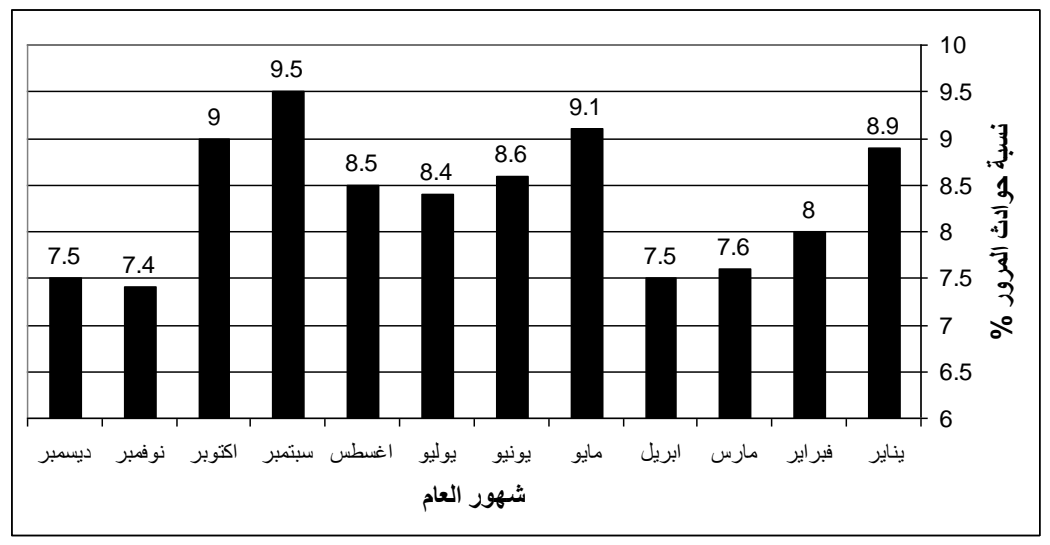

شكل رقم (8) يوضح توزيع حوادث المرور على مدار شهور العام

يشهد شهرى مايو و يونيو ارتفاع فى درجة حوادث المرور حيث بلغت نسبة المشاركة فى 17.7 \% من

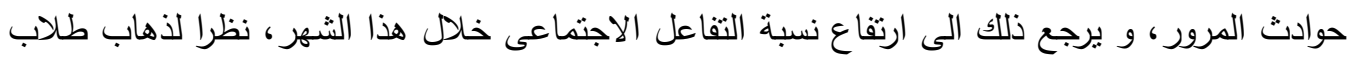

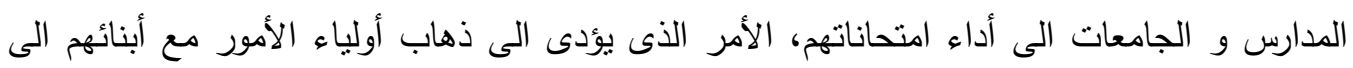

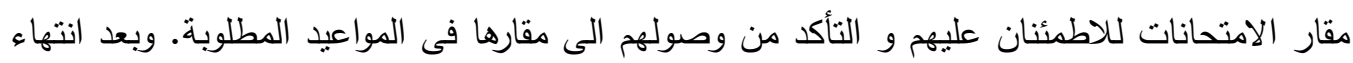
الامتحانات تخرج الأسر بعد عناء الامتحانات الى الاماكن العامة و الترويحية.

و يشهد شهر يناير ارتفاع ملحوظ فى وقوع الحوادث حيث بلغت نسبة المشاركة فى 8.9 \% من حوادث

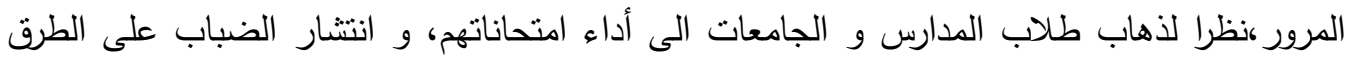
السريعة. 
و يشهد شهرى يوليو و أغسطس ارتفاع فى حوادث المرور بلغت نسبة المشاركة 16.9 \% من حوادث

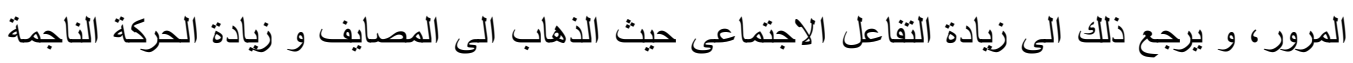

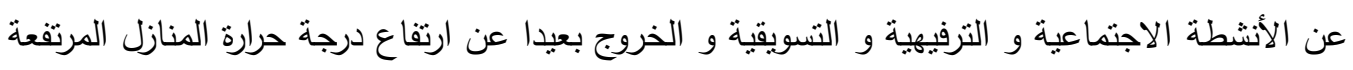

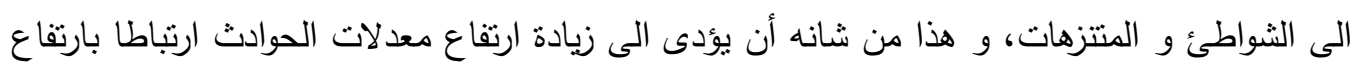
معدلات الحركة و التفاعل خلال تلاك الفترة.

تتهد شهور منتصف الفصول الدراسية انخفاضا فى حوادث المرور نظرا لطبيعة الاستقرار فى العملية

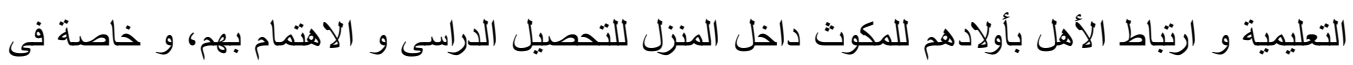

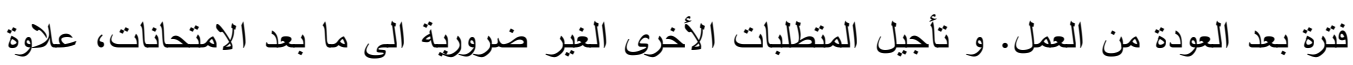
على عدم تحسن الأحوال المناخية فى نوفمبر و ديسمبر .

\section{4}

جاءت نتائج الدراسة للمتغيرات المؤثرة على حوادث المرور بمصر كما يلى: أولا: الإنسان كعنصر حاضر فى حوادث المرانة المرور : جاءت نسبة المشاركة فى حوادث المرور لأسباب ترجع الى سائق المركبة و اخرى الى الى المشاة كالتالى:

الأسباب المتصلة بالطبيعة الفيزيقية للسائق كالتعب و الإرهاق (2 \%)، النوم أثناء القيادة (5 \%)

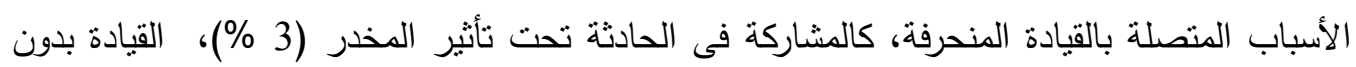
رخصة (3 \%). الأسباب المتصلة بالقيادة الخشنة، كالقيادة بسرعة عالية (23 \%)، عدم ترك مسافة كافية بين السيارات .(\% 13)

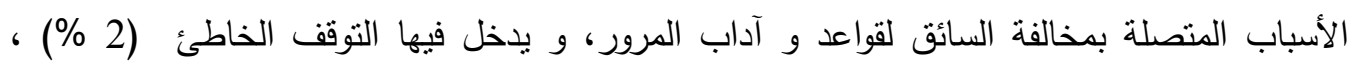

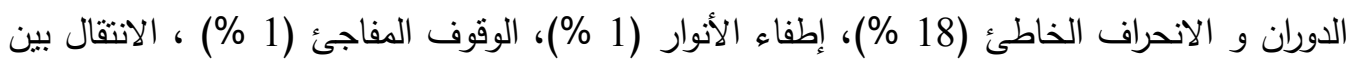

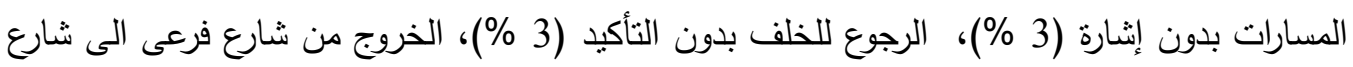
رئيسى (12 1\%). الأسباب المنصلة بالمشاة كالعبور المفاجئ (31 \% \%)، السير فى طريق السيارات (19 \%)، لعب (العبات

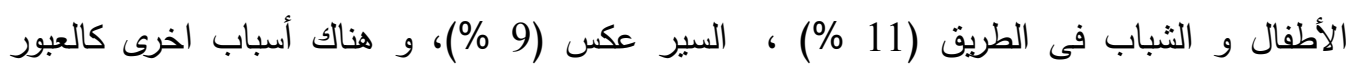

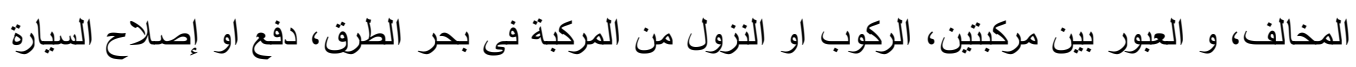

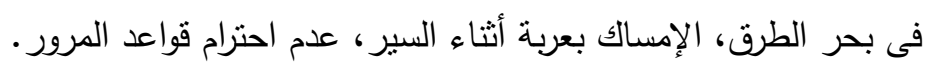
ثانيا: حوادث المرور - المنطقة و المكان: 
يعتبر مكان وقوع الحادث من المتغيرات الهامة المسببة لحوادث المرور، و يتدرج المكان من كونه منطقة وقوع الحادث، الى طبيعة هذه المنطقة من حيث طبيعتها التضاريسية، او طبيعة استخدامها و شكل الحياة فيها. كذلك يدخل فى نطاق المكان النقطة التى وقعت عندها الحادثة هل هى طريق، هل هى دوار (بؤرة) ام تقاطع. و كذلك حالة الطريق ذاتها، و مدى ملائمته للسير عليه، إذ يعتبر هو الآخر من العناصر التى لها دورها فى وقوع حادثة المرور • و جاءت نتائج الدراسة فى المناطق المختارة كالتالى:

نسبة المشاركة فى حوادث المرور خارج المدينة على الطرق السريعة 57 \% . نسبة المشاركة فى حوادث المرور فى وسط المدينة (المنطقة التجارية) 19 \% نسبة المشاركة فى حوادث المرور داخل المدينة (المنطقة السكنية) 13 \% . و فى محاولة التعرف على مكان وقوع الحادث بالتحديد كانت إجابة عينة البحث كما يلى: الأماكن التى نشهد كثافة عالية من الحوادث كالطرق الرئيسية 19 \%٪، الطرق المستقيمة 16 \% الطريق ذو المسارين فأكثز 13 \% الأماكن التى تتهد مستوى متوسطا من الحوادث كالطريق المنحنى 8 \%؛ تقاطع الطرق 7 \%؛ الدوار (البؤرة) 6 ( )

مجموعة الأماكن التى نتهد معدلات منخفضة من حوادث المرور نسبيا، كمطالع و منازل الكبارى ، الأنفاق، الطرق الفرعية، و يرجع ذلك الى البطئ الثديد فى سرعة السير و درجة الحذر العالية فى ثلك الأماكن. و بذللك فان مكانا معينا يثهد درجة عالية او منخفضة من حوادث المرور بالنظر الى الاعتبارات التالية:

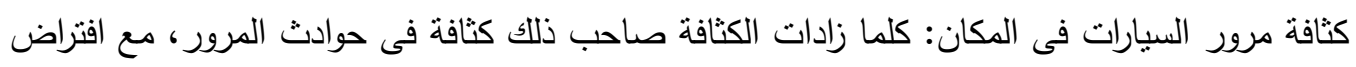
ثبات العوامل الأخرى. درجة السرعة العالية: حيث انه كلما أتاح المكان درجة سرعة عالية، زادت احتمالية وقوع نسبة عالية من الحوادث، و العكس صحيح ، مع افتراض ثبات العوامل الأخرى. درجة الحذر: حيث انه كلما تطلب المكان الذى يسير فيه المرور درجة عالية من الوعى و الحذر و ملاحظة قواعد المرور بدقة قلت احتمالية وقوع الحوادث، و العكس صحيح، مع افتراض ثبات العوامل

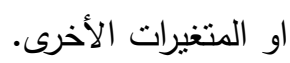
و فى محاولة التعرف على نأثير خصائص الطريق و دوره فى حوادث المرور جاءت النتائج كالتالى:نسبة المشاركة فى حوادث المرور نتيجة وجود عوائق بالطريق 24 \%؛ وجود حفر و المطبات 17 \%، الطريق الترابى 13 \%، المنحنيات المفاجئة دون التتبيه بها بمسافة كافية قبل الوصول إليها 10 \%؛ 
الطريق تحت الإنشاء 9 \%، الطريق الزلق 7 \%، عدم وجود إثشارات مرور 6 \%، الطريق المنحدر 6 \%

ثالثا: توزيع حوادث المرور بالنظر الى متغير الزمان

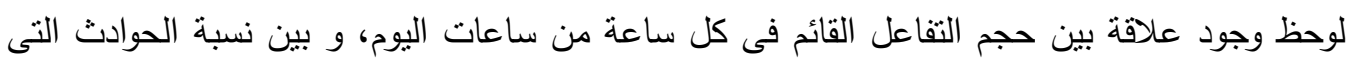

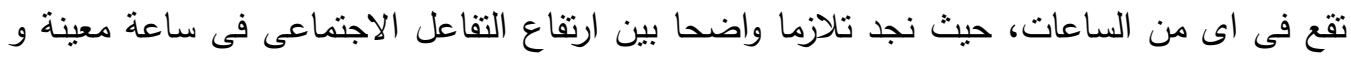
بين ارتفاع نسبة الحوادث التى تقع فى هذه الساعة، و جاءت نسبة المشاركة فى حوادث المرور كالتالى:

من الواحدة صباحا و حتى الرابعة صباحا 3.6 \%, لان التفاعل الاجتماعى يكون منخفضا للغاية.

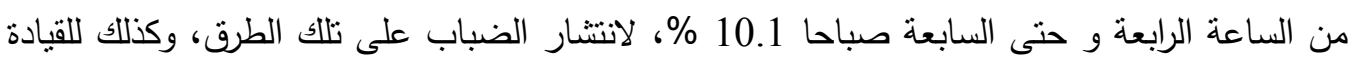
بسرعات عالية لانخفاض كثافة المرور فى تلأك الفترة.

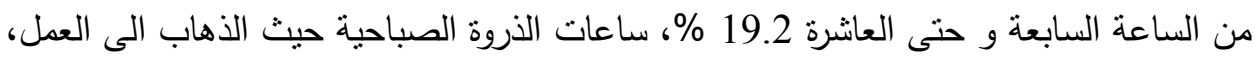

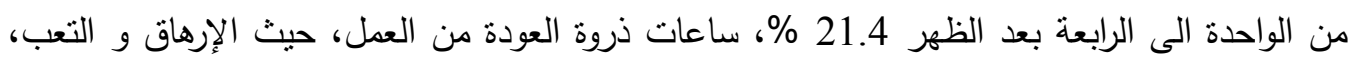

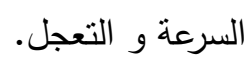

من الساعة السادسة و حتى التاسعة مساء 16.1 \%، حيث الكثافة الدرورية العالية لأداء الأنشطة الاجتماعية، التسويقية، التزفيهية، خلافه.

من الساعة التاسعة الى الثانية عشرة 5.7 \%، لطول فنرة العودة الى المنزل. معدلات وقوع الحوادث جاءت مختلفة باختلاف حجم التفاعل فى أيام الأسبوع كالتالى: -

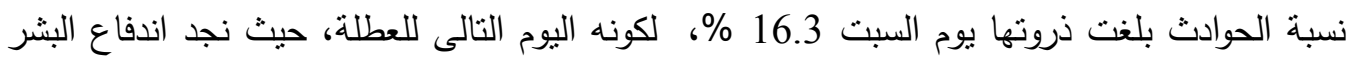

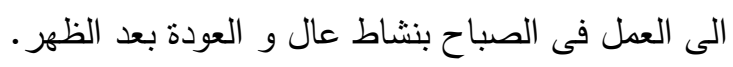
ثم يبدأ الاندفاع يقل تدريجيا حتى يوم الأربعاء، و بالتالى تقل نسبة الحوادث كذأ كذألك تدريجيا. يوم الخميس 15.9 \%، لزيادة الأنشطة الاجتماعية لكون اليوم التالى يوم عطلة.

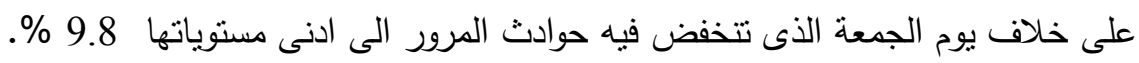
بالنسبة لأيام الثهر لم نحصل على فروق لها معنى. فى حين نجد أن ارتفاع مستويات التفاعل خلال

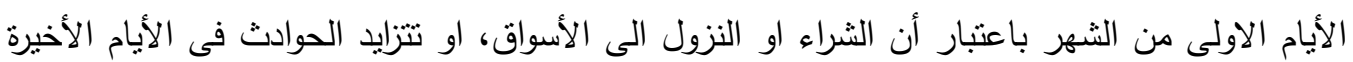

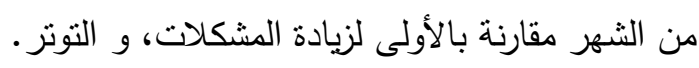

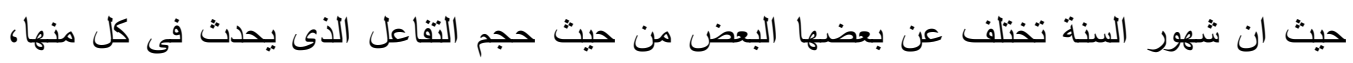

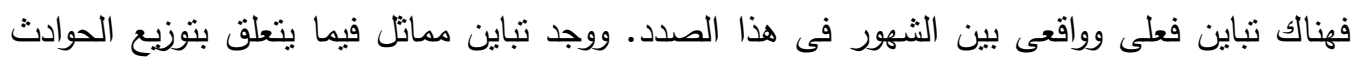

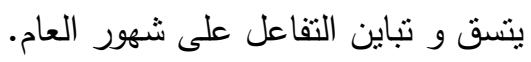


نسبة المشاركة فى سبتمبر و أكتوبر 18.5 \% ، لارتفاع التفاعل الاجتماعي، حيث قضاء الحاجات الخاصة بالأولاد فى بداية دخول المدارس، و العودة باندفاع نحو العمل و المدارس بعد أجازة طويلة. مايو و يونيو 17.7 \%، و يرجع ذلك طبيعة التفاعل الاجنماعى، حيث امتحانات نهاية العام. يناير 8.9 \% امتحانات منتصف العام، انتشار الضباب على الطرق السريعة. يوليو و أغسطس 16.9 \%، لزيادة التفاعل الاجتماعى حيث الأجازة الصيفية الطويلة. و بذلك نجد تلازما واضحا بين طبيعة التفاعل الاجتماعى فى فترة معينة بين نسبة الحوادث التى تقع فى تلاك الفنرة.

\section{5 - 5 الخلاصة و التوصيات}

إذا كان الإنسان عنصر حاضر فى حوادث المرور ، سواء كان سائقا او من المشاة ، فان ذلك يعنى أن إعداد هذا العنصر و تأهيله سوف يساعد بالتأكيد على تخفيض حوادث المرور . توجيه و إرشاد قائد المركبة بعدم القيادة عند التعب و الإرهاق، النوم أثناء القيادة، تحت نأثير المخدر، عدم إجادته للقيادة و حمله رخصة بإجادته لها ، القيادة بسرعة عالية، ضرورة نرك مسافة كافية بين السيارات، التوقف فى ألاماكن الصحيحة، الدوران و الانحراف بصورة سليمة، إنارة الأنوار و التأكد من لن عمها، التتبه عند الوقوف ، الانتقال بين المسارات باستخدام الإشارة، التأكيد عند الرجوع للخلف ، إتباع الأسلوب السليم عند الخروج من شارع فرعى الى شارع رئيسى. توجيه و إرشاد المشاة بعدم القيام بالسلوكيات الخاطئة كالعبور المفاجئ، السير فى طريق السيارات، لعب رلب الأطفال و الثباب فى الطريق ، السير عكس الاتجاه، العبور المخالف، و العبور بين مركبتين، الركوب او النزول من المركبة فى بحر الطرق، دفع او إصلاح السيارة فى بحر الطرق، الإمساك بعربة أثناء السير، عدم احترام قواعد المرور .

نسبة المشاركة فى حوادث المرور خارج المدينة على الطرق السربعة بلغت 57 \% ف فللك يعنى ضرورة الاهتمام بنلك الطرق، و مراقبتها مروريا، و توقيع المخالفات الرادعة للقيادة بسرعة تفوق المسموح بها ـ نسبة المشاركة فى حوادث المرور فى وسط المدينة (المنطقة التجارية) بلغت 19 \% فذلك يعنى ضرورة زيادة نواجد رجال المرور بتللك المنطقة و تتظيم حركة المرور نظرا للكثافة المرورية العالية. ضرورة زيادة تواجد رجال المرور فى الأماكن التى تتهد كثافة عالية من الحوادث كالطرق الرئيسية، الطرق المستقيمة ، الطريق ذو المسارين، الأماكن التى تشهد كثافة متوسطة من الحوادث الطريق المنحنى، تقاطع الطرق، الدوار (البؤرة). ضرورة وضع العلامات الإرشادية على كافة الطرق من حيث السرعات، الانحناءات، التقاطعات، اماكن الانتظار ، أماكن الخدمة، مطالع و منازل الكبارى ، الأنفاق. 
توجيه و إرشاد قائد المركبة بضرورة توخى الحذر فى القيادة فى حالة، وجود عوائق بالطريق، وجود

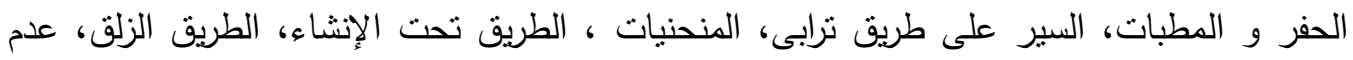
وجود إثشارات مرورية، الطريق المنحدر ، الازدحام المرورى.

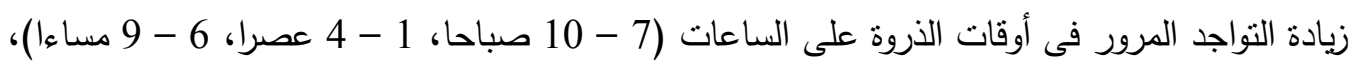
الأيام (يومى السبت و الخميس)، الثهور (سبتمبر و أكتوبر - مايو و يونيو - يناير).

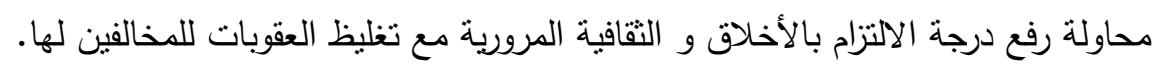

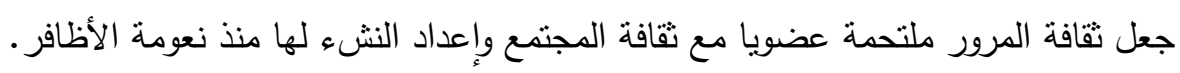

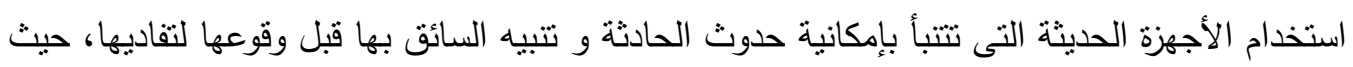
يمكن لها التتبؤ بمدى يقظة السائق، و سرعة الاستجابة للمواقف المرورية المختلفة، اختلال عجلة القيادة بيده، مدى إجادته للقيادة، نسبة الكحول بالدم و مدى الخطورة عند القبادة، المسافة البينية المطلوبة بين

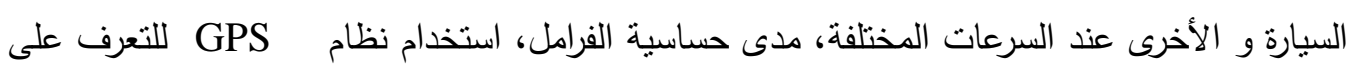
الطريق، الكثافة المرورية عليه [17] ، حالة الطقس، انسب الطرق للوصول للهدف المنشود.

\section{6- REFERENCES}

1- جريدة الثرق الاوسط 19 اكتوبر 2000، القاهرة تستضيف مؤتمر سلامة الطرق , (1977) ,

[2] Nattamen, R. and Summala, H. (1977), "Road user behaviour and traffic accident", American Elsevier, Amsterdam.

[3] Kenneth Stephenson Cliff, (1984) "Accidents: Causes, Prevention, and Services", Taylor, \& Francis, London.

[4] Marc Green \& John Senders, "Human Error in Road Accidents", http://www.visualexpert.com/Resources/roadaccidents.html

[5] Hennessy, Dwight A., and Wiesenthal, David L., (1997) "The relationship between traffic congestion, driver stress and direct versus indirect coping behaviours", Ergonomics, Vol. 40, No. 3, pp. 348-361.

[6] Yagil, Dana, (1998), "Gender and age-related differences in attitudes toward traffic laws and traffic violations", Transportation Research Part F 1, pp.123-135.

[7] Arnett, J.J., Offer, D. and Fine, M.A., (1997), "Reckless driving in adolescence: 'state' and 'trait' factors", Accident Analysis and Prevention, Vol. 29, No. 1, pp. 5763.

[8] National Highway Traffic Safety Administration, (1998b), "National Survey of Speeding and Other Unsafe Driver Actions", Volume II: Driver Attitudes and Behaviour,http://nhtsa.dot.gov/people/injury/aggressive/unsafe/att-beh/covtoc.html

[9] Parry, M.H. (1968), "Aggression on the Road", American Sociological review, p. $897-901$.

[10] Goehring, J. B., (2000), "Aggressive Driving: Background and Overview Report", National Conference of State Legislatures, http://www.ncsl.org/programs/esnr/aggrdriv.htm 
[11] R.W. Rivers, (2006), "Evidence in Traffic Crash Investigation and Reconstruction", Charles Thomas Publisher, LTD, USA.

[12] OECD, (1999), "Safety Strategies for Rural Roads", Published by OECD Publishing, New York.

[13] R.W. Rivers, (1999), "Traffic Accident Investigators' and Reconstruction", Charles Thomas Publisher, LTD, USA.

[14] Assum, Terje, (1997), "Attitudes and road accident risk", Accident Analysis and Prevention, Vol. 29, No. 2, pp.153-159.

[15] Jay Dix, Michael Graham, randy Hanzlick, (2000), "Investigation of Road Traffic Fatalities (Causes of Death)", Taylor \& Francis Group, Ltc, USA.

[16] Katsuya Matsunaga, (1996) "Insufficient headway and unforeseen greater stopping distance as combined factors in traffic accidents", the First Japan-Finland Joint Meeting on Traffic Safety, Finnish Psychological Association, Turku, Finland, August 27-29.

[17] Hayashi, M. Nishioka, A. Goshi, K. Matsunaga, (2007) "Human-Centered Intelligent Transport System ASSIST: Innovative Computing, Information and Control", 2007. ICICIC '07. Second International Conference on, 5-7 Sept. 